\title{
The selective intercalation of organic carboxylates and sulfonates into hydroxy double salts
}

\author{
Gareth R. Williams, ${ }^{1}$ John Crowder, ${ }^{1}$ Jonathan C. Burley ${ }^{2}$ and Andrew M. Fogg ${ }^{3}$ \\ 1 School of Human Sciences, Faculty of Life Sciences, London Metropolitan
} University, 166-220 Holloway Road, London, N7 8DB.

${ }^{2}$ Laboratory of Biophysics and Surface Analysis, School of Pharmacy, Boots Science Building, University of Nottingham, University Park, Nottingham, NG7 2RD.

${ }^{3}$ Department of Chemistry, University of Liverpool, Crown Street, Liverpool, L69 $7 Z D$

* Author for correspondence. Email: g.williams@londonmet.ac.uk; tel: +44 (0) 207 133 2565; fax: +44 (0) 2071334149. 


\section{Abstract}

This paper reports the first systematic investigation of the selectivity of organic guest intercalation into hydroxy double salts. The organic guests 1,2- and 1,4benzenedicarboxylate (1,2- and 1,4-BDC) have been incorporated into a range of hydroxy double salts by anion exchange. Intercalates of $\left[\mathrm{Zn}_{5}(\mathrm{OH})_{8}\right]\left(\mathrm{NO}_{3}\right)_{2} \cdot y \mathrm{H}_{2} \mathrm{O}$, $\left[\mathrm{Zn}_{5}(\mathrm{OH})_{8}\right] \mathrm{Cl}_{2} \cdot y \mathrm{H}_{2} \mathrm{O},\left[\mathrm{Zn}_{5}(\mathrm{OH})_{8}\right]\left(\mathrm{CH}_{3} \mathrm{COO}\right)_{2} \cdot y \mathrm{H}_{2} \mathrm{O},\left[\mathrm{Zn}_{3} \mathrm{Ni}_{2}(\mathrm{OH})_{8}\right]\left(\mathrm{NO}_{3}\right)_{2} \cdot y \mathrm{H}_{2} \mathrm{O}$, and $\left[\mathrm{Zn}_{3.8} \mathrm{Co}_{1.2}(\mathrm{OH})_{8}\right]\left(\mathrm{NO}_{3}\right)_{2} \cdot y \mathrm{H}_{2} \mathrm{O}$ were prepared, and the resultant materials fully characterized. 1,5- and 2,6-napthalanedisulfonate (1,5- and 2,6-NDS) were also successfully intercalated into the $\left[\mathrm{Zn}_{5}(\mathrm{OH})_{8}\right]\left(\mathrm{NO}_{3}\right)_{2} \cdot y \mathrm{H}_{2} \mathrm{O}$ material. It was found that the initial anions are almost completely replaced by the new organic guests in the majority of cases. Selected reactions were investigated by in situ X-ray diffraction, and the reactions observed to proceed directly from the host to the product largely under nucleation control. No intermediate phases were detected. The competitive intercalation of isomeric pairs of guest anions was explored, and very high degrees of preferential intercalation found for 1,4- over 1,2-BDC into all hydroxy double salts (HDSs) studied, and for 2,6- over 1,5-NDS into $\left[\mathrm{Zn}_{5}(\mathrm{OH})_{8}\right]\left(\mathrm{NO}_{3}\right)_{2} \cdot y \mathrm{H}_{2} \mathrm{O}$. The selectivity was found to be largely invariant with reaction time, reaction temperature, solvent system, and guest concentration. It was also observed to be very similar across all the HDSs explored. In situ diffraction and NMR demonstrate that the selective intercalation is a thermodynamically-controlled phenomenon. It is therefore suggested that preferential intercalation is governed in the main by the strength of the interactions between the HDS layers and the guest ions. 


\section{Introduction}

In this paper, we report the use of hydroxy double salts (HDSs) for the separation of mixtures of isomeric organic guest anions. These molecules are commonly prepared via precursors generated in mixtures from crude oil, ${ }^{1-3}$ and hence a cheap and facile separation method is of industrial interest. This is the first time that the competitive intercalation of organic guests into HDSs has been systematically studied.

HDSs are a family of solid state materials with the generic formula $\left[\mathrm{M}^{2+}(\mathrm{OH})_{2-x}\right] \mathrm{X}^{z^{-}}$ $x / z \cdot n \mathrm{H}_{2} \mathrm{O}$. They comprise positively charged metal hydroxide layers with $\mathrm{X}^{z^{-}}$anions and water molecules located in the interlayer space. A range of metal (II) cations can be incorporated into the structure, for instance $\mathrm{Zn}, \mathrm{Cu}, \mathrm{Ni}$, or Co. Materials with mixtures of cations are also known. Similarly, X can comprise any or a mixture of anions such as $\mathrm{CH}_{3} \mathrm{COO}^{-}, \mathrm{NO}_{3}{ }^{-}$or $\mathrm{Cl}^{-}$. The interlayer anions may be easily replaced through an ion exchange process, and via this route a wide range of anions including simple inorganic species (e.g. $\left.\mathrm{ClO}_{4}^{-}, \mathrm{MnO}_{4}^{-}, \mathrm{SO}_{4}{ }^{2-}\right),{ }^{5,6}$ metal complexes, ${ }^{7-9}$ alkyl sulfates, ${ }^{4}$ carboxylic acids, ${ }^{10-14}$ thiophenes, ${ }^{15}$ and a dye ${ }^{16}$ have been intercalated. It is clear therefore that the ion exchange route offers the potential to incorporate a wide range of functional anions into the HDS host matrix.

However, HDSs have received relatively little attention compared to the related layered double hydroxide (LDH) family of materials. The latter have the same key structural features of positively charged layers and anions located in the interlamellar space, but LDHs differ from HDSs in that their layers contain a mixture of trivalent and mono- or divalent metal cations. One particular aspect of LDH chemistry which has been the focus of attention is that of selective intercalation. It has been found that when an $\mathrm{LDH}$ is reacted with pairs of isomeric anions (e.g. 1,2- and 1,4benzenedicarboxylate; 1,2- and 1,4-BDC), a high degree of selectivity for one isomer over another is often seen. The result of this is that one isomer is intercalated preferentially, frequently to a very high degree $(>95 \%$ of the intercalated guests comprising one isomer). A range of isomer mixtures have been explored by a number of scientists. For instance, fumarate is found to be intercalated preferentially over maleate into the $\mathrm{LDH} \quad\left[\mathrm{LiAl}_{2}(\mathrm{OH})_{6}\right] \mathrm{Cl} \cdot \mathrm{H}_{2} \mathrm{O} \quad\left(\mathrm{LiAl}_{2}-\mathrm{Cl}\right),{ }^{17}$ and also into $\left[\mathrm{Mg}_{2} \mathrm{Al}(\mathrm{OH})_{6}\right] \mathrm{Cl} \cdot 1.5 \mathrm{H}_{2} \mathrm{O} .{ }^{18} \mathrm{LiAl}_{2}-\mathrm{Cl}$ has also been found to preferentially intercalate 
1,4-BDC over 1,2-BDC with $>95 \%$ selectivity. ${ }^{17}$ The same preferential intercalation of $1,4-\mathrm{BDC}$ occurs for the $\left[\mathrm{Ca}_{2} \mathrm{Al}(\mathrm{OH})_{6}\right] \mathrm{NO}_{3} \cdot 2 \mathrm{H}_{2} \mathrm{O} \mathrm{LDH},{ }^{19}$ and other $\mathrm{LDH}$ systems such as $\left[\mathrm{MAl}_{4}(\mathrm{OH})_{12}\right]\left(\mathrm{NO}_{3}\right)_{2} \cdot y \mathrm{H}_{2} \mathrm{O}(\mathrm{M}=\mathrm{Zn}, \mathrm{Cu}, \mathrm{Ni}$, or $\mathrm{Co}) \cdot{ }^{20}$ Analogous trends are observed for nitrophenols (4-nitrophenol is intercalated in preference to the 2- and 3nitrophenol isomers). ${ }^{21}$ A comprehensive investigation of the selectivity of isomeric benzoate anions was undertaken by Lei et al., and it was determined that generally 4isomers were preferred for intercalation. ${ }^{22}$ The researchers proposed that the calculated dipole moment of the anions may be a good predictor for preferential intercalation. Selective intercalation has also been reported for pyridinecarboxylates. ${ }^{23}$

The exploration of LDH selective intercalation has been extended to more complex guests such as herbicides. ${ }^{24} \mathrm{~A}$ series of chlorophenoxyacetates was studied, and the order of preferred intercalation found to be: 4-chlorophenoxyacetate $>2,4-$ dichlorophenoxyacetate $>$ 2,4,5-trichlorophenoxyacetate. Furthermore, O'Hare and co-workers have investigated the intercalation of nucleoside monophosphate mixtures; the selectivity observed suggested that LDHs may have potential for the separation of biomolecules. ${ }^{25}$ Other biomolecules which have been explored include muconates. $^{26}$ Beyond this, Yoshioka and co-workers performed a series of experiments in which they first intercalated naphthalene disulfonates into a $\mathrm{Mg} / \mathrm{Al}$ $\mathrm{LDH}$, and then investigated the uptake of anisole and 1,3-dinitrobenzene (1,3-DNB) from aqueous solutions. It was determined that the electron richness of the benzene rings in the sulfonate guests was key to determining the extent of uptake of anisole and $1,3-\mathrm{DNB} .^{27}$

Only minimal work has been performed to study the selective intercalation of HDSs. A preliminary study was carried out by Kadokawa et al. in $2000 .^{11}$ These authors observed that 2-napthalenecarboxylate was intercalated into $\left[\mathrm{Zn}_{5}(\mathrm{OH})_{8}\right]\left(\mathrm{NO}_{3}\right)_{2} \cdot y \mathrm{H}_{2} \mathrm{O}$ preferentially over the 1-isomer, and that 2,6-naphthalenediscarboxylate was incorporated to a greater extent than its 2,7 -isomer. This is the only example of the selective intercalation of organic guests into HDSs we have been able to find in the literature. However, recently Thomas and Rajamathi have investigated the selective intercalation of inorganic anions. The preferential intercalation of halide $\left(\mathrm{F}^{-}, \mathrm{Cl}^{-}, \mathrm{Br}^{-}\right.$ and $\left.\mathrm{I}^{-}\right)$anions into the HDSs $\left[\mathrm{Zn}_{5}(\mathrm{OH})_{8}\right]\left(\mathrm{NO}_{3}\right)_{2} \cdot y \mathrm{H}_{2} \mathrm{O}^{28}$ and $\mathrm{Co}_{3}(\mathrm{OH})_{4}\left(\mathrm{NO}_{3}\right)_{2}{ }^{29}$ was studied, and the order of preferential intercalation found to be $\mathrm{F}^{-}>\mathrm{Cl}^{-}>\mathrm{Br}^{-}>\mathrm{I}^{-}$. The 
intercalation of some divalent anions was also explored for $\mathrm{Co}_{3}(\mathrm{OH})_{4}\left(\mathrm{NO}_{3}\right)_{2}{ }^{29}$ A selectivity series $\mathrm{CO}_{3}{ }^{2-}>\mathrm{C}_{2} \mathrm{O}_{4}{ }^{2-}>\mathrm{SO}_{4}{ }^{2-}$ was observed. A previous study additionally found that $\left[\mathrm{Ni}_{1-\mathrm{x}} \mathrm{Zn}_{\mathrm{x}}(\mathrm{OH})_{2}\right]\left(\mathrm{CH}_{3} \mathrm{COO}\right)_{2} \cdot y \mathrm{H}_{2} \mathrm{O}$ HDS materials are able to selectively take up $\mathrm{Se}(\mathrm{IV})$ oxoanions in the presence of $\mathrm{Cl}^{-}{ }^{30}$

Benzenedicarboxylates and naphthalenedisulfonates, chemicals of industrial interest, were selected for investigation in this work. The 1,4-isomer of benzenedicarboxylate is used for polyester synthesis. Industrially, benzenedicarboxylates (BDCs) are generated by oxidizing xylenes, ${ }^{1,2}$ which are in turn derived from crude oil. As the xylenes are produced in mixtures, mixtures of BDCs will result from direct oxidation of the crude xylene. It is hence desirable to be able to effect a facile and environmentally friendly separation of the useful 1,4-isomer from other species. Currently, this is normally achieved by selective crystallisation or adsorption of the xylenes, but this route is relatively ineffective. Similarly naphthalenedisulfonates, important organic synthons, are prepared by analogous routes to BDCs and can be challenging to separate using conventional methods. ${ }^{3}$

In this paper, the selective intercalation chemistry of HDSs with isomeric dicarboxylate and disulfonate guests is explored systematically for the first time. Four organic guests (1,2- and 1,4-benzenedicarboxylate; 1,5- and 2,6naphthalenedisulfonate: see Figure 1) have been incorporated into a range of $\mathrm{Zn}$ containing HDSs, and the resulting products fully characterized. An in situ energydispersive X-ray diffraction study was performed to investigate the reaction mechanisms and kinetics. The selectivity for isomeric pairs of guests was subsequently investigated, and the effects of temperature, reaction time, guest excess, and HDS composition are elucidated. Experiments were additionally performed to determine the mechanism by which selectivity arises, and the results of these are explained. 


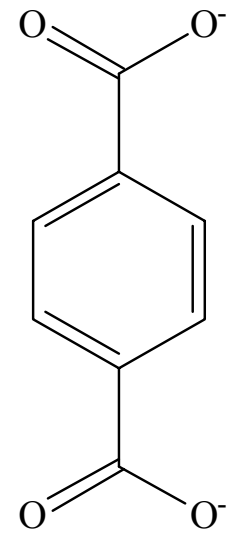

(a)

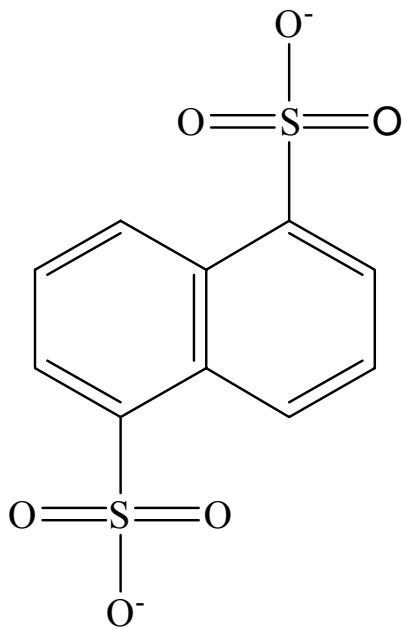

(c)

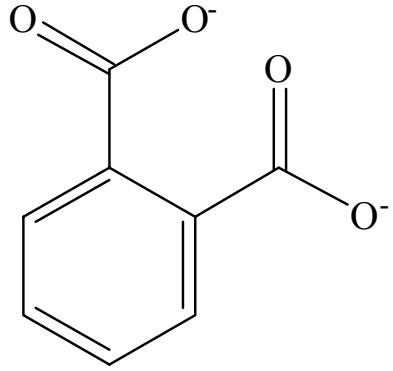

(b)<smiles>O=S(=O)([O-])c1ccc2cc(S(=O)(=O)[O-])ccc2c1</smiles>

(d)

Figure 1: The chemical structures of (a) 1,4-BDC; (b) 1,2-BDC; (c) 1,5-NDS; and, (d) 2,6-NDS.

\section{Experimental}

\section{Characterisation}

\section{X-ray diffraction}

X-ray diffraction (XRD) was performed using a Philips PW1830 instrument operating at $40 \mathrm{kV}$ and $25 \mathrm{~mA}$. $\mathrm{Cu} \mathrm{K} \alpha$ radiation $(\lambda=1.5418 \AA)$ was employed. Samples were 
finely ground and mounted on stainless steel plates for measurement. Diffracted intensity from the steel did not interfere with sample characterisation.

\section{IR spectroscopy}

IR spectra were recorded on a Bruker Vector 22 instrument fitted with an attenuated total reflectance (ATR) attachment. Data were recorded from 4000 to $650 \mathrm{~cm}^{-1}$ with resolution of $2 \mathrm{~cm}^{-1}$.

\section{Nuclear magnetic resonance spectroscopy}

${ }^{1} \mathrm{H}$ nuclear magnetic resonance (NMR) was performed on a Bruker Avance $500 \mathrm{MHz}$ spectrometer. $\mathrm{D}_{2} \mathrm{O}$ was used as the solvent.

\section{Elemental microanalysis}

$\mathrm{C}, \mathrm{H}$, and $\mathrm{N}$ contents were determined using the quantitative combustion technique on a Carlo Erba CE1108 elemental analyser. The metal contents of samples were assessed using X-ray fluorescence. Samples were first diluted with $\mathrm{CuO}$, and elemental contents then determined on an Oxford Instruments X-Met 3000TXR+ instrument.

\section{In situ X-ray diffraction}

In situ energy-dispersive X-ray diffraction measurements were performed on Beamline F3 of the DORIS synchrotron at the Deutsches Elektronen-Synchrotron (DESY), Hamburg, Germany. The beamline is supplied with white-beam X-rays over the energy range 13.5 to $65 \mathrm{keV}$. Reactions were performed in borosilicate glass vessels using the Oxford-Daresbury in situ reaction vessel, the details of which have

previously been reported. ${ }^{31}$ In a typical experiment, $0.25 \mathrm{~g}(0.4 \mathrm{mmol})$ of the desired HDS was combined with $10 \mathrm{~mL}$ of a solution containing $1.6 \mathrm{mmol}$ of the guest ion. This was then heated using a temperature-controlled furnace system. Diffraction patterns were recorded every 60s until changes in these patterns had ceased. 
Data were then analysed by two independent methods. The first method involved using the F3 Tool software, provided by DESY. In brief, reflections were identified and Gaussian functions fitted to these. The reflections were then integrated at each timepoint. All fits were inspected by eye to ensure that reflections were well modeled by the chosen function. The integrated data were subsequently probed using the Avrami-Erofe'ev model; more details are given in the results section. The second method comprised a Principal Component Analysis (PCA) according to a previous report. ${ }^{32}$ Statistical analyses were undertaken using the " $R$ '" package (http://rproject.org) and the pcaMethods module. ${ }^{33}$ PCA involves taking a number of correlated variables in a large dataset (diffracted intensity, peak position, time, etc in the present case) and reducing these to a smaller number of orthogonal variables known as "principal components", or PCs. Subsequent PCs account for increasingly small amounts of variance in the dataset (i.e. the greatest amount of variance is accounted for by PC1, a smaller amount by PC2, and so forth).

\section{Synthesis}

\section{Hydroxy double salt syntheses}

All materials were procured from Sigma-Aldrich, Fluka, or Alfa-Aesar and were used as supplied. $\left[\mathrm{Zn}_{5}(\mathrm{OH})_{8}\right]\left(\mathrm{NO}_{3}\right)_{2} \cdot y \mathrm{H}_{2} \mathrm{O}$ was prepared by reaction of $\mathrm{ZnO}(4.2 \mathrm{~g})$ and $\mathrm{Zn}\left(\mathrm{NO}_{3}\right)_{2} \cdot 6 \mathrm{H}_{2} \mathrm{O}(24.1 \mathrm{~g})$ in $60 \mathrm{~mL}$ deionised water. The reaction mixture was stirred for 7 days at room temperature, and the solid product recovered by vacuum filtration. The resultant white powder was washed with copious amounts of deionised water, a small amount of acetone, and then allowed to dry under vacuum for $c a .30 \mathrm{~min}$.

Other HDSs were prepared using analogous procedures. $\left[\mathrm{Zn}_{3.8} \mathrm{Co}_{1.2}(\mathrm{OH})_{8}\right]\left(\mathrm{NO}_{3}\right)_{2} \cdot y \mathrm{H}_{2} \mathrm{O}\left(\mathrm{Zn}_{3.8} \mathrm{Co}_{1.2}-\mathrm{NO}_{3}\right)$ was generated from $\mathrm{ZnO}(3.0 \mathrm{~g})$ and $\mathrm{Co}\left(\mathrm{NO}_{3}\right)_{2} \cdot 6 \mathrm{H}_{2} \mathrm{O}(8.73 \mathrm{~g})$ in $18 \mathrm{~mL}$ water. $\left[\mathrm{Zn}_{3} \mathrm{Ni}_{2}(\mathrm{OH})_{8}\right]\left(\mathrm{NO}_{3}\right)_{2} \cdot y \mathrm{H}_{2} \mathrm{O}\left(\mathrm{Zn}_{3} \mathrm{Ni}_{2}-\mathrm{NO}_{3}\right)$ was synthesized using $\mathrm{ZnO}(3.0 \mathrm{~g})$ and $\mathrm{Ni}\left(\mathrm{NO}_{3}\right)_{2} \cdot 6 \mathrm{H}_{2} \mathrm{O}(8.73 \mathrm{~g})$ in $18 \mathrm{~mL}$ deionised water. $\left[\mathrm{Zn}_{5}(\mathrm{OH})_{8}\right] \mathrm{Cl}_{2} \cdot y \mathrm{H}_{2} \mathrm{O}\left(\mathrm{Zn}_{5}-\mathrm{Cl}\right)$ was prepared using $\mathrm{ZnO}(3.0 \mathrm{~g})$ and $\mathrm{ZnCl}_{2}(7.26$ $\mathrm{g})$ in $18 \mathrm{~mL}$ water, and $\left[\mathrm{Zn}_{5}(\mathrm{OH})_{8}\right]\left(\mathrm{CH}_{3} \mathrm{COO}\right)_{2} \cdot y \mathrm{H}_{2} \mathrm{O}\left(\mathrm{Zn}_{5}\right.$-acetate) from $\mathrm{ZnO}(3.0 \mathrm{~g})$ and $\mathrm{Zn}\left(\mathrm{CH}_{3} \mathrm{COO}\right)_{2} \cdot 2 \mathrm{H}_{2} \mathrm{O}(8.05 \mathrm{~g})$ in $18 \mathrm{~mL} \mathrm{H} \mathrm{H}_{2} \mathrm{O}$. All products were recovered by vacuum filtration and washed as described above. All the materials synthesised were 
found to be powders, with the all- $\mathrm{Zn}$ materials being white in colour, the $\mathrm{Zn}_{3.8} \mathrm{Co}_{1.2^{-}}$ $\mathrm{NO}_{3}$ material pink, and the $\mathrm{Zn}_{3} \mathrm{Ni}_{2}-\mathrm{NO}_{3}$ material a green-blue colour.

\section{Intercalation}

Intercalation of the organic anions was achieved by combining $0.2 \mathrm{mmol}$ of an HDS with an 8-fold excess of the guest dianions. Disodium salts were used for 1,4-BDC, 1,5-NDS, and 2,6-NDS, and the dipotassium salt for 1,2-BDC. $10 \mathrm{~mL}$ of deionised water was added to the solid materials, and the mixture stirred at $60{ }^{\circ} \mathrm{C}$ for 6 days. The solid products were recovered by vacuum filtration, washed, and dried as described above.

\section{Competitive intercalation}

Competitive intercalation reactions were undertaken as follows. $0.2 \mathrm{mmol}$ of the HDS was reacted with $10 \mathrm{~mL}$ of a solution containing a four-fold excess $(0.8 \mathrm{mmol})$ of each isomer (e.g. for the BDC reactions, the HDS was reacted with a solution containing $0.8 \mathrm{mmol}$ of 1,2-BDC and $0.8 \mathrm{mmol}$ of 1,4-BDC). Reactions were performed for varying times and at different temperatures to probe the influence of these parameters on selectivity. Reactions were also performed using reduced excesses of the guest anions: for a 2-fold excess $0.2 \mathrm{mmol}$ of HDS was reacted with $0.4 \mathrm{mmol}$ of each guest, and for stoichiometric experiments with $0.2 \mathrm{mmol}$ of each guest. The solid products from each reaction were worked up as detailed above.

\section{Deintercalation}

Guest recovery was performed by reacting $50 \mathrm{mg}$ of the intercalation compound with a 15 -fold excess of $\mathrm{Na}_{2} \mathrm{CO}_{3}$ in $3 \mathrm{~mL} \mathrm{D}_{2} \mathrm{O}$ at $80{ }^{\circ} \mathrm{C}$ overnight. The reaction mixtures were then filtered and the filtrate analysed by ${ }^{1} \mathrm{H}$ NMR.

\section{Time-resolved NMR experiment}

The competitive intercalation of $1,2-$ and $1,4-\mathrm{BDC}$ was studied at $90{ }^{\circ} \mathrm{C}$ by combining $\mathrm{Zn}_{5}-\mathrm{NO}_{3}(0.500 \mathrm{~g} ; 0.8 \mathrm{mmol})$ with $40 \mathrm{~mL}$ of an aqueous solution containing a 4-fold excess of both 1,2- and 1,4-BDC (3.2 mmol of each). Aliquots $(1 \mathrm{~mL})$ were taken at 
given time points, and quenched by rapid filtration. $500 \mu \mathrm{L}$ of each aliquot was taken and combined with $500 \mu \mathrm{L}$ of an $80 \mathrm{mmol} \mathrm{dm}^{-3}$ succinic acid solution in $\mathrm{D}_{2} \mathrm{O}$. These solutions were analysed by ${ }^{1} \mathrm{H}$ NMR, and the succinic acid internal standard used to calculate the concentrations of 1,2- and 1,4-BDC in solution at each point in time.

\section{Results}

\section{Intercalation of organic acids into $\mathbf{Z n}_{5}-\mathrm{NO}_{3}$}

\section{X-ray diffraction}

It proved facile to intercalate the organic species 1,2- and 1,4-benzenedicarboxylate (1,2- and 1,4-BDC) and 1,5- and 2,6-napthalenedisulfonate (1,5- and 2,6-NDS) into the HDS $\left[\mathrm{Zn}_{5}(\mathrm{OH})_{8}\right]\left(\mathrm{NO}_{3}\right)_{2} \cdot y \mathrm{H}_{2} \mathrm{O}\left(\mathrm{Zn}_{5}-\mathrm{NO}_{3}\right)$ through an anion exchange approach. The chemical structures of the anions are given in Figure 1. Successful intercalation was clearly evidenced by X-ray diffraction (XRD), IR spectroscopy, and elemental microanalysis. The XRD patterns of the reaction products do not display any of the characteristic reflections of the starting material, and the $h 00$ basal reflections are observed to shift to lower angle, suggesting an increase in interlayer spacing consistent with the incorporation of a larger anion. XRD data for the $\mathrm{Zn}_{5}-\mathrm{NO}_{3}$ starting material and its 1,2- and 1,4-BDC intercalates $\left(\mathrm{Zn}_{5}-1,2-\mathrm{BDC}\right.$ and $\left.\mathrm{Zn}_{5}-1,4-\mathrm{BDC}\right)$ are presented in Figure 2. The interlayer spacing is seen to increase from $9.7 \AA$ with $\mathrm{Zn}_{5}$ $\mathrm{NO}_{3}$ to $14.2-15.0 \AA$ for the BDC intercalates and to $15.4-15.7 \AA$ for the NDScontaining materials. All the patterns show peak broadening indicative of stacking defects, with that of $\mathrm{Zn}_{5}-1,2-\mathrm{BDC}$ showing broader peaks than the other two materials. Full data are included in Table 1. An XRD pattern of the 2,6-NDS intercalate may be found in Figure S1(a). 


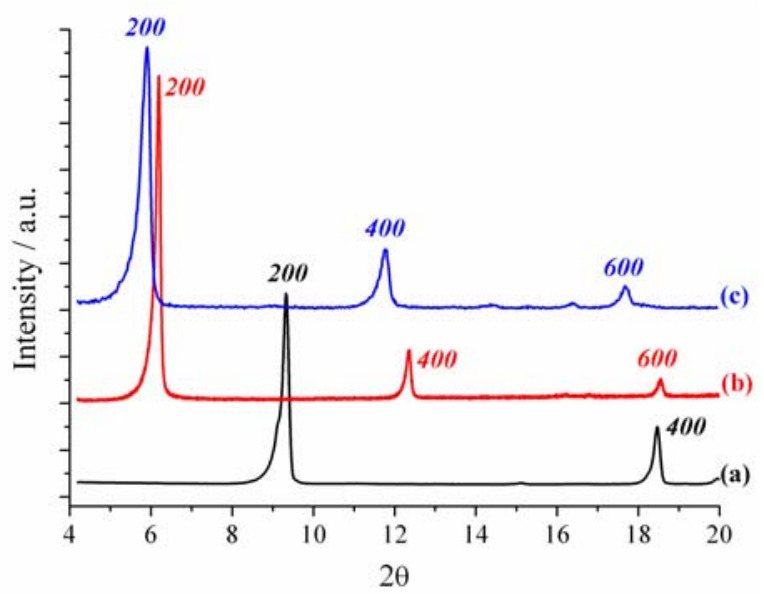

Figure 2: X-ray diffraction patterns of (a) $\mathrm{Zn}_{5}-\mathrm{NO}_{3}$; (b) $\mathrm{Zn}_{5}-1,4-\mathrm{BDC}$, and (c) $\mathrm{Zn}_{5}-1,2-\mathrm{BDC}$.

Table 1: A summary of the X-ray diffraction and elemental analysis data on the HDS-organic intercalation compounds.

\begin{tabular}{|c|c|c|c|c|}
\hline Host & Guest & $\begin{array}{r}\text { Interlayer } \\
\text { spacing / A }\end{array}$ & Formula & $\begin{array}{c}\text { Elemental contents / \% } \\
\text { obs. (calc.) }\end{array}$ \\
\hline \multirow{4}{*}{$\mathrm{Zn}_{5}-\mathrm{NO}_{3}$} & $1,2-\mathrm{BDC}$ & 15.0 & {$\left[\mathrm{Zn}_{5}(\mathrm{OH})_{8}\right]\left(\mathrm{C}_{8} \mathrm{H}_{4} \mathrm{O}_{4}\right)_{0.95}\left(\mathrm{NO}_{3}\right)_{0.1} \cdot 3 \mathrm{H}_{2} \mathrm{O}$} & $\begin{array}{l}\text { C } 13.8 \text { (13.6); H } 2.82 \text { (2.65); } \\
\text { N } 0.58 \text { (0.21); Zn } 47.8 \text { (47.6) }\end{array}$ \\
\hline & 1,4-BDC & 14.2 & {$\left[\mathrm{Zn}_{5}(\mathrm{OH})_{8}\right]\left(\mathrm{C}_{8} \mathrm{H}_{4} \mathrm{O}_{4}\right)_{0.975}\left(\mathrm{NO}_{3}\right)_{0.05} \cdot 3 \mathrm{H}_{2} \mathrm{O}$} & $\begin{array}{l}\text { C } 14.2(13.9) ; \text { H } 2.82(2.66) ; \\
\text { N } 0.42(0.10) ; \text { Zn } 47.6(47.5)\end{array}$ \\
\hline & $1,5-\mathrm{NDS}$ & 15.4 & {$\left[\mathrm{Zn}_{5}(\mathrm{OH})_{8}\right]\left(\mathrm{C}_{10} \mathrm{H}_{6} \mathrm{~S}_{2} \mathrm{O}_{6}\right)_{0.9}\left(\mathrm{NO}_{3}\right)_{0.2} \cdot 3 \mathrm{H}_{2} \mathrm{O}$} & $\begin{array}{l}\text { C } 13.9 \text { (13.8); H } 2.76(2.49) ; \\
\text { N } 0.49(0.36) ; \text { Zn } 39.7(41.0)\end{array}$ \\
\hline & 2,6-NDS & 15.7 & {$\left[\mathrm{Zn}_{5}(\mathrm{OH})_{8}\right]\left(\mathrm{C}_{10} \mathrm{H}_{6} \mathrm{~S}_{2} \mathrm{O}_{6}\right)_{0.9}\left(\mathrm{NO}_{3}\right)_{0.2} \cdot 3 \mathrm{H}_{2} \mathrm{O}$} & $\begin{array}{l}\text { C } 13.9(13.8) ; \text { H } 2.78(2.49) ; \\
\text { N } 0.42(0.36) ; \text { Zn } 42.9(41.0)\end{array}$ \\
\hline \multirow{2}{*}{$\mathrm{Zn}_{5}-\mathrm{Cl}$} & 1,2-BDC & 14.6 & & $\begin{array}{c}\text { C } 14.2 \text { (14.2); H } 2.83 \text { (2.67); } \\
\text { Zn 48.3 (47.5) }\end{array}$ \\
\hline & 1,4-BDC & 14.3 & {$\left[\mathrm{Zn}_{5}(\mathrm{OH})_{8}\right]\left(\mathrm{C}_{8} \mathrm{H}_{4} \mathrm{O}_{4}\right) \cdot 3 \mathrm{H}_{2} \mathrm{O}$} & $\begin{array}{c}\text { C } 14.0 \text { (14.2); H } 2.86 \text { (2.67); } \\
\text { Zn 46.3 (47.5) }\end{array}$ \\
\hline \multirow{2}{*}{$\mathrm{Zn}_{5}$-acetate } & $1,2-\mathrm{BDC}$ & 14.3 & {$\left[\mathrm{Zn}_{5}(\mathrm{OH})_{8}\right]\left(\mathrm{C}_{8} \mathrm{H}_{4} \mathrm{O}_{4}\right)_{0.85}\left(\mathrm{CH}_{3} \mathrm{CO}_{2}\right)_{0.3} \cdot 2 \mathrm{H}_{2} \mathrm{O}$} & $\begin{array}{c}\text { C } 13.3 \text { (13.7); H } 2.06 \text { (2.51); } \\
\text { Zn 50.0 (49.3) }\end{array}$ \\
\hline & 1,4-BDC & 14.5 & {$\left[\mathrm{Zn}_{5}(\mathrm{OH})_{8}\right]\left(\mathrm{C}_{8} \mathrm{H}_{4} \mathrm{O}_{4}\right) \cdot 3 \mathrm{H}_{2} \mathrm{O}$} & $\begin{array}{c}\text { C } 14.3 \text { (14.2); H 2.85 (2.67); } \\
\text { Zn 48.6 (47.5) }\end{array}$ \\
\hline \multirow{2}{*}{$\mathrm{Zn}_{3} \mathrm{Ni}_{2}-\mathrm{NO}_{3}$} & 1,2-BDC & 15.0 & {$\left[\mathrm{Zn}_{3} \mathrm{Ni}_{2}(\mathrm{OH})_{8}\right]\left(\mathrm{C}_{8} \mathrm{H}_{4} \mathrm{O}_{4}\right)_{0.9}\left(\mathrm{NO}_{3}\right)_{0.2} \cdot 3 \mathrm{H}_{2} \mathrm{O}$} & $\begin{array}{c}\text { C } 13.0 \text { (13.1); H } 2.47 \text { (2.67); N } 0.6 \\
\text { (0.43); Zn } 29.2(30.8) ; \\
\text { Ni } 17.6(18.2)\end{array}$ \\
\hline & 1,4-BDC & 14.3 & {$\left[\mathrm{Zn}_{3} \mathrm{Ni}_{2}(\mathrm{OH})_{8}\right]\left(\mathrm{C}_{8} \mathrm{H}_{4} \mathrm{O}_{4}\right)_{0.95}\left(\mathrm{NO}_{3}\right)_{0.1} \cdot 3 \mathrm{H}_{2} \mathrm{O}$} & $\begin{array}{c}\text { C } 14.3 \text { (13.8); H } 2.87(2.70) ; \text { N } 0.35 \\
\text { (0.21); Zn 26.2(27.2); } \\
\text { Ni } 19.5(19.4)\end{array}$ \\
\hline \multirow{2}{*}{$\begin{array}{l}\mathrm{Zn}_{3.8} \mathrm{Co}_{1.2^{-}} \\
\mathrm{NO}_{3}\end{array}$} & 1,2-BDC & 14.8 & {$\left[\mathrm{Zn}_{3.8} \mathrm{Co}_{1.2}(\mathrm{OH})_{8}\right]\left(\mathrm{C}_{8} \mathrm{H}_{4} \mathrm{O}_{4}\right)_{0.95}\left(\mathrm{NO}_{3}\right)_{0.1} \cdot 3 \mathrm{H}_{2} \mathrm{O}$} & $\begin{array}{c}\text { C } 14.0(13.7) ; \mathrm{H} 2.84(2.67) ; \mathrm{N} 0.40 \\
(0.21) ; \mathrm{Zn} 36.2(36.5) ; \\
\text { Co } 11.3(10.6)\end{array}$ \\
\hline & 1,4-BDC & 14.3 & {$\left[\mathrm{Zn}_{3.8} \mathrm{Co}_{1.2}(\mathrm{OH})_{8}\right]\left(\mathrm{C}_{8} \mathrm{H}_{4} \mathrm{O}_{4}\right)_{0.95}\left(\mathrm{NO}_{3}\right)_{0.1} \cdot 3 \mathrm{H}_{2} \mathrm{O}$} & $\begin{array}{c}\text { C } 13.7 \text { (13.9); H } 2.86(2.67) ; \text { N } 0.38 \\
\text { (0.21); Zn } 37.0(36.5) ; \\
\text { Co } 10.1(10.6)\end{array}$ \\
\hline
\end{tabular}

\section{Guest orientation}

The layer thickness of the HDS is around $5-7.3 \AA$ (depending on whether one looks at the "flat" portions of the layers, or considers the $\mathrm{Zn}(\mathrm{OH})_{3} \mathrm{NO}_{3}$ tetrahedra protruding 
from the layers). The end-to-end lengths of the guest ions are calculated (from crystal structure data and van der Waals' radii) to be $8.4 \AA$ (1,2-BDC); $9.8 \AA$ (1,4-BDC); 9.7 $\AA$ (1,5-NDS); and, $12.5 \AA$ (2,6-NDS). A comparison of these end-to-end lengths with the gallery height (the interlayer spacing less the HDS layer thickness in the "flat" portions) gives ratios very close to 1 for $1,4-\mathrm{BDC}$ and $1,5-\mathrm{NDS}$. This suggests that the guests adopt a perpendicular monolayer arrangement in the interlayer space. This is sensible since the charged moieties lie at opposite ends of these species, and a monolayer will permit the two charged units to interact favourably with adjacent HDS layers. For 2,6-NDS, the gallery height is somewhat less that the length of the molecule, implying that a tilted monolayer might form, with the guests arranged at an angle of $c a .60^{\circ}$ to the layers. In the case of 1,2-BDC the gallery height is around 20 $\%$ greater than the size of the molecule, which is indicative of an interdigitated bilayer forming, with 1,2-BDC anions in alternating orientations. This arrangement is necessarily adopted because the carboxylate groups in 1,2-BDC are adjacent on the benzene ring, and hence both must interact with the same HDS layer. Schematics of the guest orientations adopted with 1,2- and 1,4-BDC are provided in Figure 3.

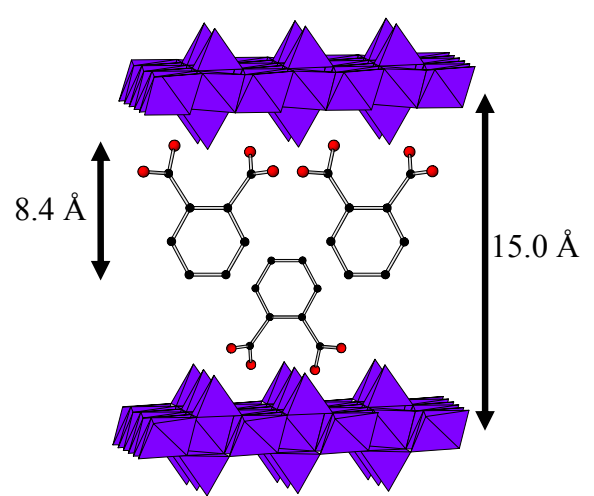

(a)

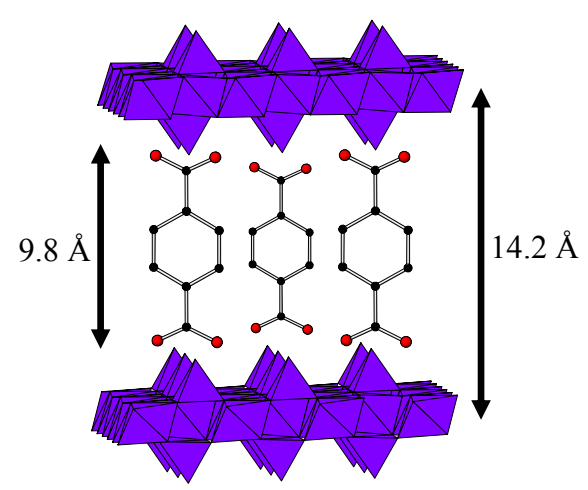

(b)

Figure 3: Schematics showing the probable orientations of the guests in (a) $\mathrm{Zn}_{5^{-}} 1,2-\mathrm{BDC}$ and (b) $\mathrm{Zn}_{5^{-}}$ 1,4-BDC.

\section{Elemental microanalysis}

Elemental microanalysis was performed to determine the $\mathrm{C}, \mathrm{H}$, and $\mathrm{N}$ contents of the samples. The metal contents were quantified using X-ray fluorescence. The $\mathrm{N}$ contents of the $\mathrm{Zn}_{5}-\mathrm{BDC}$ and $\mathrm{Zn}_{5}$-NDS compounds prepared from $\mathrm{Zn}_{5}-\mathrm{NO}_{3}$ were small, confirming almost complete replacement of the nitrate by the organic guest. 
The resultant formulae calculated are given in Table 1. It can be seen that there is always a small amount of residual nitrate remaining, even after the extended reaction time $(6 \mathrm{~d})$ and elevated temperature $\left(60^{\circ} \mathrm{C}\right)$ employed. The NDS intercalates contain around $10 \%$ of the original nitrate content, while the 1,2-BDC intercalate has around $5 \%$ and the $1,4-\mathrm{BDC}$ intercalate around $2.5 \%$.

\section{IR spectroscopy}

The intercalation compounds were additionally characterised by IR spectroscopy. Spectra of $\mathrm{Zn}_{5}-\mathrm{NO}_{3}$, the disodium salt of 1,4-BDC, and the reaction product of $\mathrm{Zn}_{5^{-}}$ $\mathrm{NO}_{3}$ and 1,4-BDC are shown in Figure 4. The spectrum of $\mathrm{Zn}_{5}-\mathrm{NO}_{3}$ (Figure 4(a)) shows typical features of an HDS. A broad absorption band centred at around 3250 $\mathrm{cm}^{-1}$ corresponds to $\mathrm{H}$-bonded $\mathrm{OH}$ groups of the HDS layers. The characteristic $\mathrm{NO}_{3}{ }^{-}$ vibration can be seen at $c a .1365 \mathrm{~cm}^{-1}$, and the $\delta$-vibration of interlayer water molecules is located at $1635 \mathrm{~cm}^{-1}$. M-O vibrations from the HDS layers occur below $1000 \mathrm{~cm}^{-1}$. The spectrum of 1,4-BDC (Figure 4(c)) displays distinctive symmetric and asymmetric carboxylate bands at 1380 and $1560 \mathrm{~cm}^{-1}$ respectively. The IR absorptions from the $\mathrm{Zn}_{5}-1,4-\mathrm{BDC}$ intercalate are a composite of those from the HDS and those from the guest. The spectrum, provided in Figure 4(d), contains a broad $\mathrm{OH}$ absorption band at around $3300 \mathrm{~cm}^{-1}$, and distinctive carboxylate vibrations at 1580 and $1380 \mathrm{~cm}^{-1}$. This demonstrates successful intercalation of the guest anion. No shoulder is visible on the $1380 \mathrm{~cm}^{-1}$ band, suggesting that only minimal nitrate remains in the compound. The shift in the position of the asymmetric carboxylate band from $1560 \mathrm{~cm}^{-1}$ in $1,4-\mathrm{BDC}$ to $1580 \mathrm{~cm}^{-1}$ in $\mathrm{Zn}_{5}-1,4-\mathrm{BDC}$ arises as a result of electrostatic and $\mathrm{H}$-bonding interactions between the $\mathrm{COO}^{-}$groups and the HDS layers. The IR data concur with the elemental analysis and XRD data to confirm successful intercalation of 1,4-BDC. These data are in excellent agreement with literature values for 1,4-BDC intercalates of LDHs. ${ }^{34-36}$ The IR spectra for all the other $\mathrm{Zn}_{5}-\mathrm{NO}_{3}$ intercalates also show the disappearance of the nitrate absorption and the presence of characteristic bands from the guest ions (the spectrum for the 2,6-NDS intercalate is given in Figure S1(b)). Hence, all four BDC and NDS anions could be incorporated into the $\mathrm{Zn}_{5}-\mathrm{NO}_{3} \mathrm{HDS}$ material. 


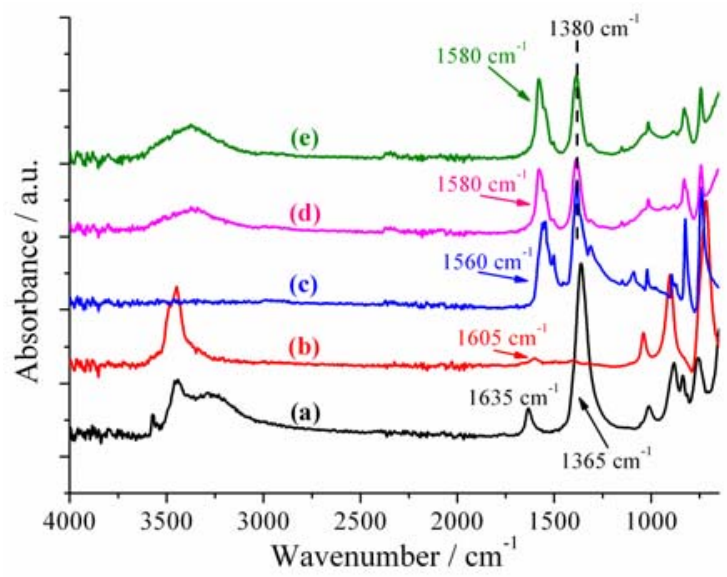

Figure 4: IR spectra of (a) $\mathrm{Zn}_{5}-\mathrm{NO}_{3}$; (b) $\mathrm{Zn}_{5}-\mathrm{Cl}$; (c) the disodium salt of 1,4-BDC; (d) the reaction product of 1,4-BDC and $\mathrm{Zn}_{5}-\mathrm{NO}_{3}$; and, (e) the reaction product of 1,4-BDC and $\mathrm{Zn}_{5}-\mathrm{Cl}$.

\section{Intercalation into other hydroxy double salts}

In order to probe the influence of the initial interlayer anion and the layer composition on intercalation, reactions were also performed with 1,2- and 1,4-BDC and the HDSs $\left[\mathrm{Zn}_{5}(\mathrm{OH})_{8}\right] \mathrm{Cl}_{2} \cdot y \mathrm{H}_{2} \mathrm{O} \quad\left(\mathrm{Zn}_{5}-\mathrm{Cl}\right), \quad\left[\mathrm{Zn}_{5}(\mathrm{OH})_{8}\right]\left(\mathrm{CH}_{3} \mathrm{COO}\right)_{2} \cdot y \mathrm{H}_{2} \mathrm{O} \quad\left(\mathrm{Zn}_{5}\right.$-acetate $)$, $\left[\mathrm{Zn}_{3} \mathrm{Ni}_{2}(\mathrm{OH})_{8}\right]\left(\mathrm{NO}_{3}\right)_{2} \cdot y \mathrm{H}_{2} \mathrm{O} \quad\left(\mathrm{Zn}_{3} \mathrm{Ni}_{2}-\mathrm{NO}_{3}\right), \quad$ and $\quad\left[\mathrm{Zn}_{3.8} \mathrm{Co}_{1.2}(\mathrm{OH})_{8}\right]\left(\mathrm{NO}_{3}\right)_{2} \cdot y \mathrm{H}_{2} \mathrm{O}$ $\left(\mathrm{Zn}_{3.8} \mathrm{Co}_{1.2}-\mathrm{NO}_{3}\right)$. The X-ray diffraction data (see Table 1 and Figure S2) show that the intercalation compounds are largely analogous to those prepared from $\mathrm{Zn}_{5}-\mathrm{NO}_{3}$. The interlayer spacings are generally higher for 1,2-BDC than for 1,4-BDC, and are broadly the same across the range of HDSs studied. The elemental analysis data indicate that virtually all of the nitrate anions are replaced by the BDC guests in the majority of cases. The exception to this is the 1,2-BDC intercalate of $\mathrm{Zn}_{5}$-acetate, where the elemental analysis data suggest that a significant proportion of the acetate is not replaced.

IR spectroscopy also confirmed successful intercalation of the BDC anions into the HDSs. Data for $\mathrm{Zn}_{5}-\mathrm{Cl}, 1,4-\mathrm{BDC}$ and the product of the reaction between 1,4-BDC and $\mathrm{Zn}_{5}-\mathrm{Cl}$ are shown in Figure 4. The IR spectrum of $\mathrm{Zn}_{5}-\mathrm{Cl}$ (Figure 4(b)) contains a slightly broadened band centred at $3450 \mathrm{~cm}^{-1}$ which corresponds to stretches of the $\mathrm{OH}$ groups in the layers and a small absorption at $1605 \mathrm{~cm}^{-1}$ arising from water bending motions, together with $\mathrm{Zn}-\mathrm{O}$ vibrational bands below $1000 \mathrm{~cm}^{-1}$. The spectrum of its reaction product with 1,4-BDC (Figure 4(e)) displays a broadened 
absorption around $3500 \mathrm{~cm}^{-1}$, reflecting the fact that the BDC carboxylate groups in the interlayer space are able to $\mathrm{H}-$ bond with the layer $\mathrm{OH}$ groups. Characteristic $\mathrm{COO}^{-}$ vibrational modes can be observed at 1580 and $1380 \mathrm{~cm}^{-1}$, confirming successful intercalation of 1,4-BDC. The IR spectra for the other intercalation compounds all exhibit analogous features, and in all cases verify that the BDC guests are incorporated into the HDS hosts.

\section{In situ diffraction study}

\section{Intercalation into $\mathrm{Zn}_{5}-\mathrm{NO}_{3}$}

The intercalation of 1,2-BDC and 1,4-BDC into $\mathrm{Zn}_{5}-\mathrm{NO}_{3}$ was studied at 70, 80, 90 ${ }^{\circ} \mathrm{C}$, and $95{ }^{\circ} \mathrm{C}$. At $70{ }^{\circ} \mathrm{C}$, the reactions were observed to be very slow, and could not be followed to anywhere near completion owing to time constraints. At $80{ }^{\circ} \mathrm{C}$ and above, the reaction proceeded more rapidly, and kinetic and mechanistic parameters could be extracted. At all temperatures, the reaction was seen to be a one-step process proceeding directly from the $\mathrm{Zn}_{5}-\mathrm{NO}_{3}$ starting material to the $\mathrm{Zn}_{5}$-BDC product. No crystalline intermediate phases were observed in the diffraction data. These results are clearly visible in the $3 \mathrm{D}$ stacked plot for the intercalation of 1,4-BDC into $\mathrm{Zn}_{5}-\mathrm{NO}_{3}$ at $90{ }^{\circ} \mathrm{C}$, which is given in Figure 5. A comparison of the datasets for 1,2- and 1,4-BDC revealed that the former exhibits a higher d-spacing in situ than the latter (15.5 vs. $14.6 \AA$ ). This is consistent with the patterns observed ex situ although the d-spacings in situ are slightly higher, presumably as a result of increased hydration (or possibly different interlayer dynamics at elevated temperatures). 


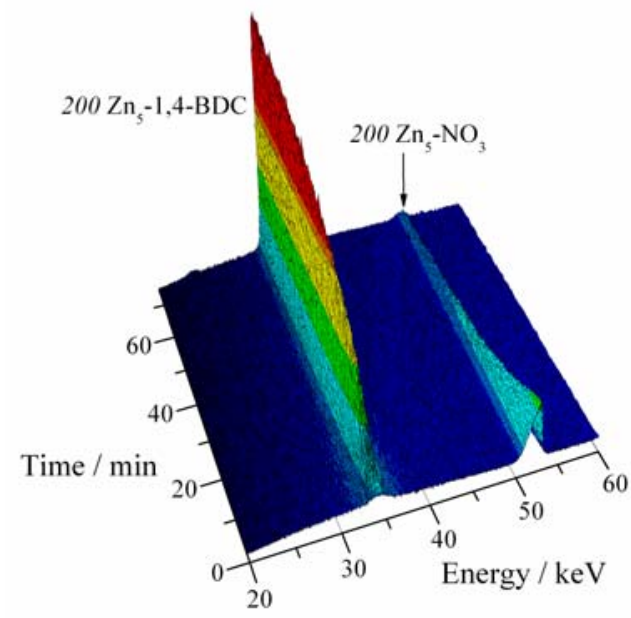

Figure 5: A 3D stacked plot showing the intercalation of 1,4-BDC into $\mathrm{Zn}_{5}-\mathrm{NO}_{3}$ at $90{ }^{\circ} \mathrm{C}$.

The intensities of the 200 reflections of the $\mathrm{Zn}_{5}-\mathrm{NO}_{3}$ and $\mathrm{Zn}_{5}-\mathrm{BDC}$ materials were integrated for each reaction, and converted into extent of reaction $v s$. time, $\alpha_{t}$ :

$\alpha_{\mathrm{t}}=\mathrm{I}_{h k l}(\mathrm{t}) / \mathrm{I}_{h k l}(\max )$

where $\mathrm{I}_{h k l}(\mathrm{t})$ is the intensity of a reflection $h k l$ at time $\mathrm{t}$, and $\mathrm{I}_{h k l}(\max )$ is the maximum intensity of that reflection.

A plot showing the change in intensity of the 200 reflections for the intercalation of 1,4-BDC into $\mathrm{Zn}_{5}-\mathrm{NO}_{3}$ is depicted in Figure 6. The $\alpha$ s. $\mathrm{t}$ curves cross at $\alpha \approx 0.5$, which confirms a one-step transformation. This crossing point indicates that the loss of diffracted intensity from the starting material is closely matched by a gain in diffraction intensity from the product, and therefore that no intermediate phases form. If an intermediate was present, a crossing point much closer to $\alpha=0$ would be expected. 


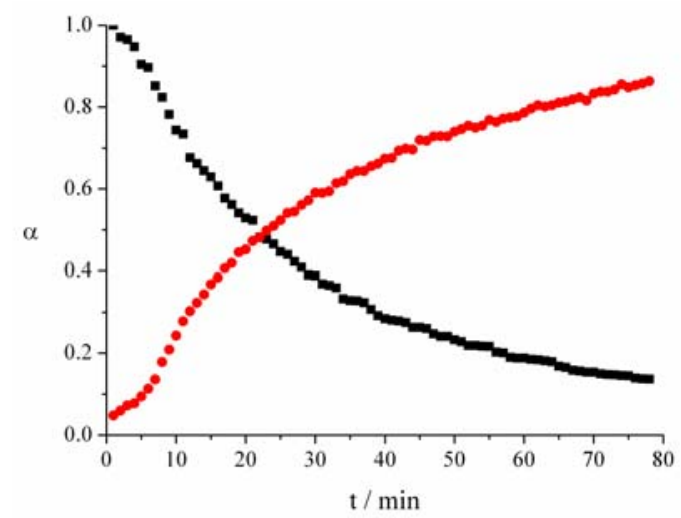

Figure 6: Extent of reaction vs. time data for the intercalation of 1,4-BDC into $\mathrm{Zn}_{5}-\mathrm{NO}_{3}$, showing the changes in intensity of the host $(\boldsymbol{\square})$ and product (O) 200 reflections at $90{ }^{\circ} \mathrm{C}$.

We have recently demonstrated that Principal Component Analysis (PCA) is a powerful method for the analysis of in situ EDXRD data, and determination of reaction mechanism. ${ }^{32}$ PCA was performed on the data recorded for BDC intercalation into $\mathrm{Zn}_{5}-\mathrm{NO}_{3}$. Exemplar results, for the intercalation of 1,4-BDC at 90 ${ }^{\circ} \mathrm{C}$ are included in Figure 7. The majority of the variance in the system (93.36\%) is accounted for by principal component (PC) 1. For reactions going directly from starting material to product, we have previously found that the change in the diffraction pattern is represented by a gradual increase in PC1, while PC2 is largely invariant. ${ }^{32}$ Where an intermediate phase exists, this is characterised by $\mathrm{PC} 2$ passing through a very distinct maximum as the reaction proceeds.

For the intercalation of $1,4-\mathrm{BDC}$ into $\mathrm{Zn}_{5}-\mathrm{NO}_{3}, \mathrm{PC} 1$ is seen to increase gradually as the reaction proceeds (Figure 7). PC2 is essentially invariant throughout the reaction. These observations are only consistent with a one-stage process. The PCA hence shows that only two phases are present in the reaction system: the $\mathrm{Zn}_{5}-\mathrm{NO}_{3}$ starting material at approximately $53 \mathrm{keV}(9.7 \AA)$ and the $\mathrm{Zn}_{5}-1,4-\mathrm{BDC}$ product at $c a .35 \mathrm{keV}$ $(14.6 \AA)$. No intermediates are visible, consistent with the results of the visual analysis. Analogous results are observed for 1,4- and 1,2-BDC intercalation at $80{ }^{\circ} \mathrm{C}$, and PCA plots are provided in Figures S3 and S4 respectively. 

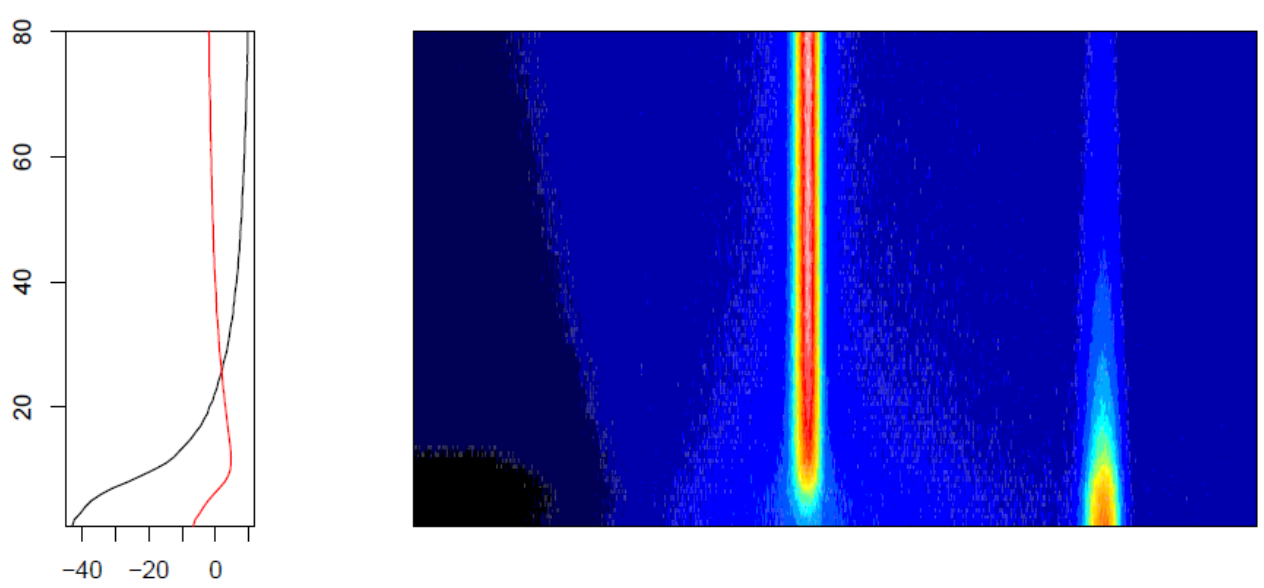

PC score

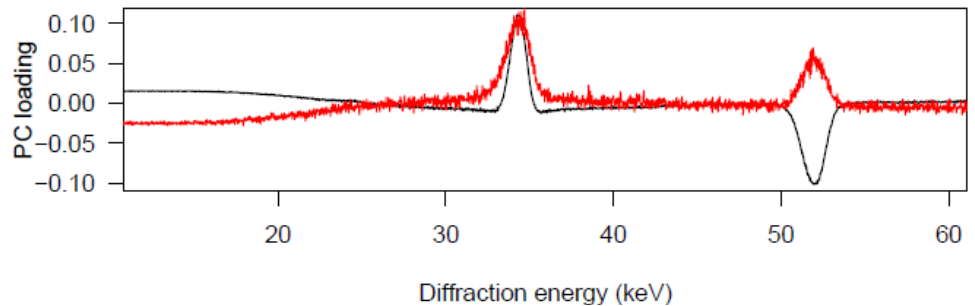

Figure 7: PCA of in situ EDXRD data for the intercalation of 1,4-BDC into $\mathrm{Zn}_{5}-\mathrm{NO}_{3}$ at $90{ }^{\circ} \mathrm{C}$. Principal component (PC) 1 is shown in black, and PC2 in red.

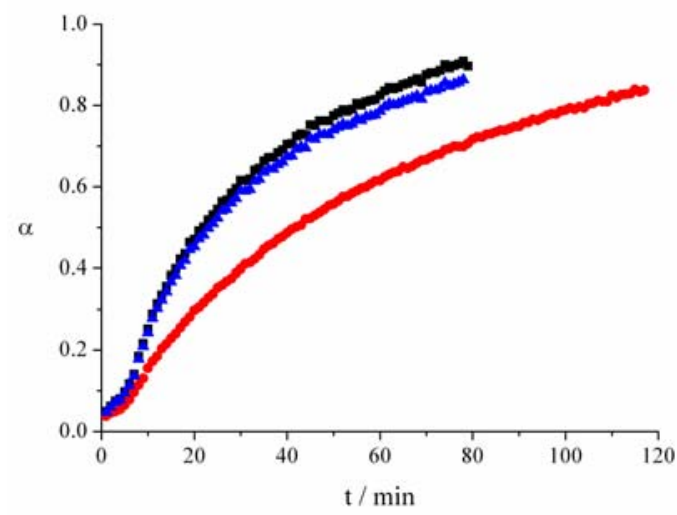

Figure 8: Extent of reaction vs. time plots for the intercalation of 1,2-BDC into $\mathrm{Zn}_{5}-\mathrm{NO}_{3}$ at $80{ }^{\circ} \mathrm{C}(\mathbf{\square})$, and for the intercalation of $1,4-\mathrm{BDC}$ at $80(\mathbf{O})$ and $90^{\circ} \mathrm{C}(\mathbf{\Delta})$.

Extent of reaction $v$ s. time curves for the intercalation of 1,4-BDC at 80 and $90{ }^{\circ} \mathrm{C}$ and 1,2-BDC at $80{ }^{\circ} \mathrm{C}$ are shown in Figure 8. The intercalation of 1,4-BDC is observed to proceed more rapidly at the higher temperature (i.e. $\alpha$ increases much more quickly). A comparison of the data for 1,2- and 1,4-BDC at $80^{\circ} \mathrm{C}$ reveal that the latter intercalates more slowly than the former. 1,2-BDC is also observed to 
intercalate more rapidly at $70{ }^{\circ} \mathrm{C}$. The experimental data were analysed using the Avrami-Erofe'ev model. This takes the form:

$$
\alpha=1-\mathrm{e}^{-\left[\mathrm{k}\left(\mathrm{t}-\mathrm{t}_{0}\right)\right]^{\mathrm{n}}}
$$

where $\alpha$ is the extent of reaction, $t_{0}$ is the induction time, $k$ is the rate, and $n$ (the reaction exponent) contains information on the reaction mechanism. ${ }^{37}$ This expression can conveniently be rearranged to give:

$\ln (-\ln (1-\alpha))=\mathrm{n} \ln \mathrm{k}+\mathrm{n} \ln \left(\mathrm{t}-\mathrm{t}_{0}\right)$

$\mathrm{t}_{0}$ is found to be zero for these systems. Sharp-Hancock plots of $\ln (-\ln (1-\alpha)) v s$. $\ln \mathrm{t}$ were generated, and are given in Figure 9. These plots are linear in shape, confirming the applicability of the Avrami-Erofe'ev model for this system. The reaction exponent $n$ can be calculated from the gradient, and the rate constant $\mathrm{k}$ from the intercept of the graph: these parameters are detailed in Table 2. For 1,4-BDC intercalation, at each temperature the reaction exponent $\mathrm{n}$ is observed to be $c a$. 1. This corresponds to a nucleation-growth reaction mechanism, with instantaneous nucleation followed by two dimensional diffusion control. The nucleation sites are the layer edges, and since all these are present at the start of the reaction we observe "instantaneous" nucleation. Two-dimensional diffusion control suggests that, once a pair of layers has been prised apart ("nucleation"), it is relatively easy for the new guest molecules to diffuse into the interlayer space: hence diffusion control operates thereafter. The rate constants, $\mathrm{k}$, can be used to estimate the activation energy for the intercalation of 1,4-BDC via the Arrrhenius model. $\mathrm{E}_{\mathrm{a}}$ is determined to be approximately $80 \mathrm{~kJ} \mathrm{~mol}^{-1}$, which is entirely consistent with a nucleation-growth process. The values observed here are similar to those reported previously in other mechanistic studies of HDS intercalation. ${ }^{12,38}$

The intercalation of $1,2-\mathrm{BDC}$ into $\mathrm{Zn}_{5}-\mathrm{NO}_{3}$ at $80{ }^{\circ} \mathrm{C}$ obeys the Avrami-Erofe'ev model and has $\mathrm{n} \approx 1$, corresponding to a nucleation-growth reaction mechanism, with instantaneous nucleation followed by two dimensional diffusion control. However, the reaction was found to be very different at $90{ }^{\circ} \mathrm{C}$ and above. At these elevated temperatures the reaction mechanism is seen to change at around $\alpha=0.6$, leading to 
markedly non-linear Sharp-Hancock plots (see Figure S5). The exponent $\mathrm{n}$ increases from 0.65 early in the reaction to 1.28 later on. This means that it is not possible to determine a rate constant value at $90{ }^{\circ} \mathrm{C}$, nor to calculate an activation energy for 1,2BDC intercalation. From the exponent values obtained, it appears that nucleation might be becoming more important later in the reaction process, but as only limited data are available no firm conclusions may be drawn.

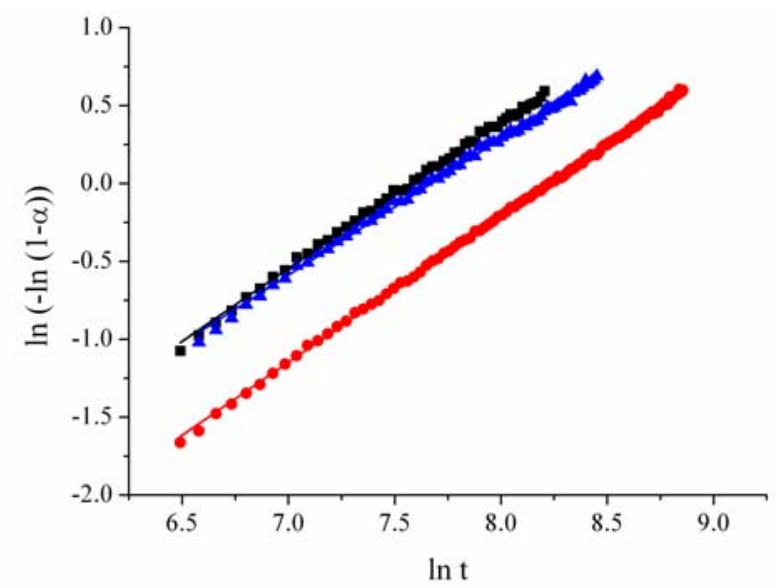

Figure 9: Sharp-Hancock plots for intercalation of 1,2-BDC into $\mathrm{Zn}_{5}-\mathrm{NO}_{3}$ at $80{ }^{\circ} \mathrm{C}(\boldsymbol{\square})$, and for the intercalation of $1,4-\mathrm{BDC}$ at $80(\boldsymbol{O})$ and $90^{\circ} \mathrm{C}(\mathbf{\Delta})$.

Table 2: Kinetic and mechanistic parameters for the intercalation of 1,2- and 1,4-BDC into $\mathrm{Zn}_{5}-\mathrm{X}$. Standard uncertainties are given in parentheses.

\begin{tabular}{|c|c|c|c|c|}
\hline Host & Guest & Temperature $/{ }^{\circ} \mathrm{C}$ & $\mathbf{n}$ & $k\left(\times 10^{-4} s^{-1}\right)$ \\
\hline \multirow{4}{*}{$\mathrm{Zn}_{5}-\mathrm{NO}_{3}$} & 1,2-BDC & 80 & $0.939(6)$ & $5.10(34)$ \\
\hline & & 80 & $0.935(2)$ & $2.67(34)$ \\
\hline & $1,4-\mathrm{BDC}$ & 90 & $0.875(5)$ & $4.65(30)$ \\
\hline & & 95 & $0.98(1)$ & $8.13(45)$ \\
\hline \multirow{4}{*}{$\mathrm{Zn}_{5}-\mathrm{Cl}$} & & 80 & $1.36(1)$ & $5.57(41)$ \\
\hline & $1,2-B D C$ & 90 & $1.45(1)$ & $7.93(62)$ \\
\hline & & 80 & $0.748(3)$ & $1.32(22)$ \\
\hline & 1,4-BDC & 90 & $0.682(3)$ & $1.86(29)$ \\
\hline \multirow{2}{*}{$\mathrm{Zn}_{3.8} \mathrm{Co}_{1.2}-\mathrm{NO}_{3}$} & 1,2-BDC & 80 & $1.92(5)$ & $24.1(4)$ \\
\hline & 1,4-BDC & 80 & $1.49(2)$ & $14.3(4)$ \\
\hline
\end{tabular}

\section{Intercalation into $\mathbf{Z n}_{5}-\mathbf{C l}$}

The intercalation of 1,2- and 1,4-BDC into $\mathrm{Zn}_{5}-\mathrm{Cl}$ was also monitored in situ. A 3D stacked plot of the raw experimental data obtained for 1,4-BDC intercalation at $90{ }^{\circ} \mathrm{C}$ is shown in Figure 10(a); additional data are provided in Figure S6. The decline in 
intensity of the $\mathrm{Zn}_{5}-\mathrm{Cl}$ and growth in intensity of the $\mathrm{Zn}_{5}$ '-1,4-BDC 200 reflections are clearly visible; also resolvable is the $\mathrm{Zn}_{5}$ '-1,4-BDC 400 reflection. The only crystalline phases observed in the system are the starting material and the product: the plot does not show any evidence for any intermediate phases. The lack of an intermediate is confirmed by the $\alpha v s$. time plots (Figure S6(a)), in which the host and product reflections intersect at $\alpha=c a$. 0.5. PCA also demonstrate unambiguously that the reaction proceeds directly from the host to the product, with no intermediate present at either temperature studied. PCA results for the reaction between $\mathrm{Zn}_{5}-\mathrm{Cl}$ and 1,4-BDC at $90{ }^{\circ} \mathrm{C}$ are shown in Figure S7. A one-step reaction is also observed for 1,2-BDC intercalation.

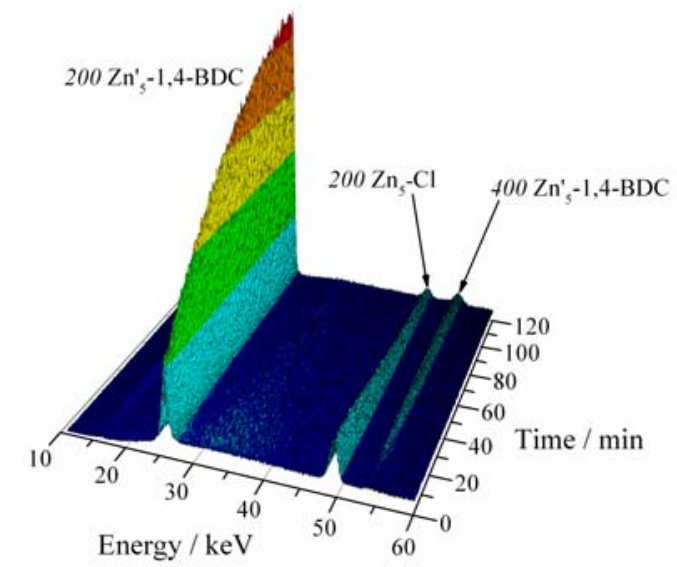

(a)

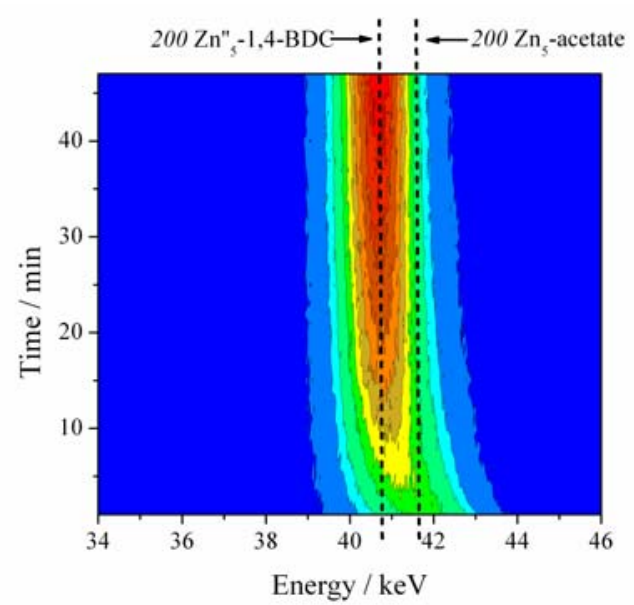

(b)

Figure 10: EDXRD data for the intercalation of 1,4-BDC into (a) $\mathrm{Zn}_{5}-\mathrm{Cl}$ and (b) $\mathrm{Zn}_{5}$-acetate at $90{ }^{\circ} \mathrm{C}$.

The Avrami-Erofe'ev model can again be used to model intercalation into $\mathrm{Zn}_{5}-\mathrm{Cl}$; its applicability here is demonstrated by the linear nature of the Sharp-Hancock plots in Figure S6(c). A summary of the germane reaction parameters is detailed in Table 2. The reaction exponent $\mathrm{n}$ is calculated to be around 0.75 for $1,4-\mathrm{BDC}$ intercalation. It is not possible to unambiguously determine the reaction mechanism from this value: a value of 1 would indicate a nucleation-growth mechanism, with 2D diffusion control following instantaneous nucleation, whereas a value of 0.5 would suggest an entirely diffusion controlled process, where nucleation plays no part in controlling the reaction rate. Since $\mathrm{n}$ for the intercalation of $1,4-\mathrm{BDC}$ into $\mathrm{Zn}_{5}-\mathrm{Cl}$ is intermediate between those two values, it may be that both mechanisms are involved in the process. The activation energy, $E_{a}$, is estimated to be around $40 \mathrm{~kJ} \mathrm{~mol}^{-1}$ from the $\mathrm{k}$ values. This is 
rather less than that for $1,4-\mathrm{BDC}$ intercalation into $\mathrm{Zn}_{5}-\mathrm{NO}_{3}$, consistent with the observation that some part of the $\mathrm{Zn}_{5}-\mathrm{Cl}$ reaction might be diffusion controlled. This energy is comparable to that obtained for other anion exchange intercalation processes. $^{39}$

As for intercalation into $\mathrm{Zn}_{5}-\mathrm{NO}_{3}, 1,2-\mathrm{BDC}$ is observed to intercalate much more rapidly than 1,4-BDC (see Table 2). For 1,2-BDC intercalation, the value of $n$ is around 1.5, suggesting that the mechanism may involve deceleratory nucleation followed by 2D diffusion control. The nucleation sites in this system can be regarded as the layer edges. A fixed number $e$ of edges will exist at the start of the reaction. Assuming that all the nucleation sites are identical, all will have an equal probability $p$ of nucleating at any point in time. Therefore, at the start of reaction the nucleation rate may be expressed as ep. As the reaction proceeds, some nucleation sites $r$ will have reacted, and hence will no longer be available for reaction. Thus, the number of nucleation sites is reduced to $e-r$, and the rate of nucleation will decline to $(e-r) p$, meaning that nucleation slows with time. A very rough estimate of the activation energy for 1,2-BDC intercalation yields a value of around $10 \mathrm{~kJ} \mathrm{~mol}^{-1}$ : this is much lower than that for 1,4-BDC, consistent with the more rapid reaction rates observed with the former guest.

\section{Intercalation into $\mathbf{Z n}_{5}$-acetate}

The reaction of 1,4-BDC with $\mathrm{Zn}_{5}$-acetate (see Figure $10(\mathrm{~b})$ ) was monitored at $90{ }^{\circ} \mathrm{C}$. This dataset is rather difficult to evaluate because there is overlap between the 200 reflections of the starting material and the product. It is not possible to unambiguously deconvolute these reflections. However, it appears that there is no reaction intermediate, and PCA (Figure S8) confirms this.

\section{Intercalation into $\mathrm{Zn}_{3.8} \mathrm{Co}_{1.2}-\mathrm{NO}_{3}$}

EDXRD data for the intercalation of 1,2- and 1,4-BDC at $80{ }^{\circ} \mathrm{C}$ are displayed in Figure S9. Kinetic parameters are included in Table 2. As for the other systems studied, 1,2-BDC is observed to intercalate more rapidly than the 1,4- analogue. The 
exponent $\mathrm{n}$ is found to be between 1 and 2, suggesting a mechanism of deceleratory nucleation followed by 2D diffusion control as discussed above.

\section{Competitive intercalation}

\section{Intercalation into $\mathrm{Zn}_{5}-\mathrm{NO}_{3}$}

\section{Benzenedicarboxylate guests}

The competitive intercalation of 1,2- and 1,4-BDC into $\mathrm{Zn}_{5}-\mathrm{NO}_{3}$ was studied as a function of time, temperature, and solvent with a four-fold excess of each anion used for reaction. Powder XRD patterns recorded after each reaction closely resembled the pattern of $\mathrm{Zn}_{5}-1,4-\mathrm{BDC}$, suggesting that the reaction might be selective for this anion. After short reaction times (1d), some starting material was clearly visible alongside the 1,4-BDC intercalate. In order to assess selectivity more quantitatively, the $\mathrm{Zn}_{5}$ BDC materials were reacted with $\mathrm{Na}_{2} \mathrm{CO}_{3}$ in $\mathrm{D}_{2} \mathrm{O}$ to give $\left[\mathrm{Zn}_{5}(\mathrm{OH})_{8}\right] \mathrm{CO}_{3} \cdot y \mathrm{H}_{2} \mathrm{O}$, and the BDC guests released into solution quantified by ${ }^{1} \mathrm{H}$ NMR (via integration of characteristic resonances from each $\mathrm{BDC}$ isomer).

All the parameters investigated were found to have only a minor influence on the overall selectivity exhibited: in all the reaction conditions studied, the HDS was observed to be more than $90 \%$ selective for the 1,4-BDC isomer (i.e. more than $90 \%$ of the intercalated guest was 1,4-BDC). The results of competitive intercalation reactions conducted for 6 days at various temperatures are given in Figure 11. There is a small increase in 1,4-BDC uptake with elevation of the temperature from 20 to 40 ${ }^{\circ} \mathrm{C}$, but no further increase is seen beyond this. At $20{ }^{\circ} \mathrm{C}$, around $95 \%$ of the intercalated anions comprise 1,4-BDC, and at $40{ }^{\circ} \mathrm{C}$ and above the selectivity for $1,4-$ BDC is $>98 \%$. Full numerical data are provided in the Supporting Information, Table S1. Changing the reaction time also has a relatively small impact on the selectivity. After 4 days of reaction, very similar results are seen. At room temperature, the HDS is around $95 \%$ selective for $1,4-\mathrm{BDC}$, and this increases to $c a$. $98 \%$ at $40{ }^{\circ} \mathrm{C}$ and above (see ESI, Table S2 and Figure S10). 


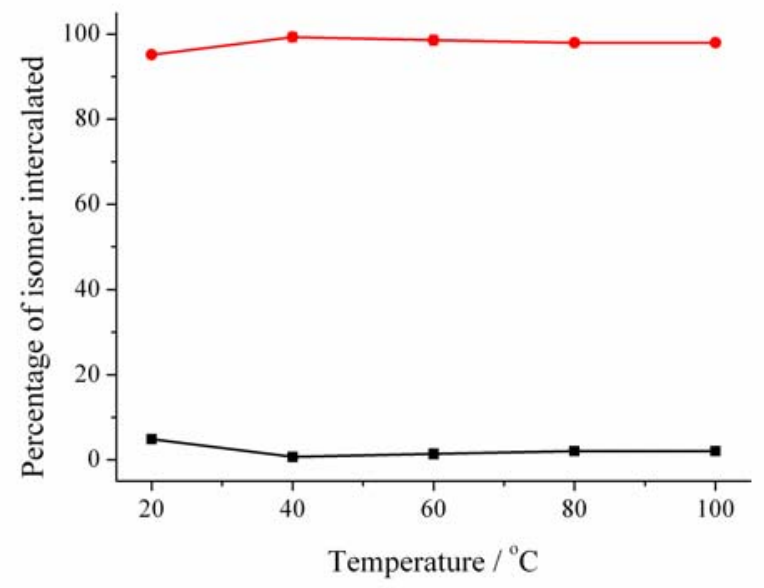

Figure 11: The results of the competitive intercalation of 1,2- (ם) and 1,4-BDC (O) into $\mathrm{Zn}_{5}-\mathrm{NO}_{3}$ for 6 days in water, with a 4-fold excess of guest employed. Experiments were performed in triplicate and mean \pm S.D. are plotted (error bars are so small as to be contained within the points on the graph here)

Analogous results were observed after 1 day of reaction $(94 \pm 0.06 \%$ selectivity for 1,4-BDC at room temperature, $100 \%$ at $100{ }^{\circ} \mathrm{C}$ ), even though there was clearly some unreacted $\mathrm{Zn}_{5}-\mathrm{NO}_{3}$ remaining after the room temperature reaction process. Increasing the reaction time to 23 days caused a small uplift in selectivity at $20{ }^{\circ} \mathrm{C}$, with $98 \%$ selectivity for $1,4-\mathrm{BDC}$ at room temperature and $100 \%$ at $100{ }^{\circ} \mathrm{C}$. It is hence clear that in water and with a 4-fold excess of each guest present the $\mathrm{Zn}_{5}-\mathrm{NO}_{3} \mathrm{HDS}$ is highly selective for 1,4-BDC under all temperature and time conditions studied. Increasing the reaction time and temperature causes only a small increase in selectivity.

The role of the solvent in selectivity was next probed, with reactions performed in a $50 / 50(\mathrm{v} / \mathrm{v})$ water / acetone mixture. Analogous trends to those seen for reactions in water are observed after 4 and 6 days of reaction (see Figure 12 for the results of 6day reactions): as the temperature is increased, there is generally a small increase in selectivity for 1,4 -BDC from $94.6 \%$ at $20{ }^{\circ} \mathrm{C}$ to $99.3 \%$ at $100{ }^{\circ} \mathrm{C}$. Full data are listed in Tables S3 and S4. 


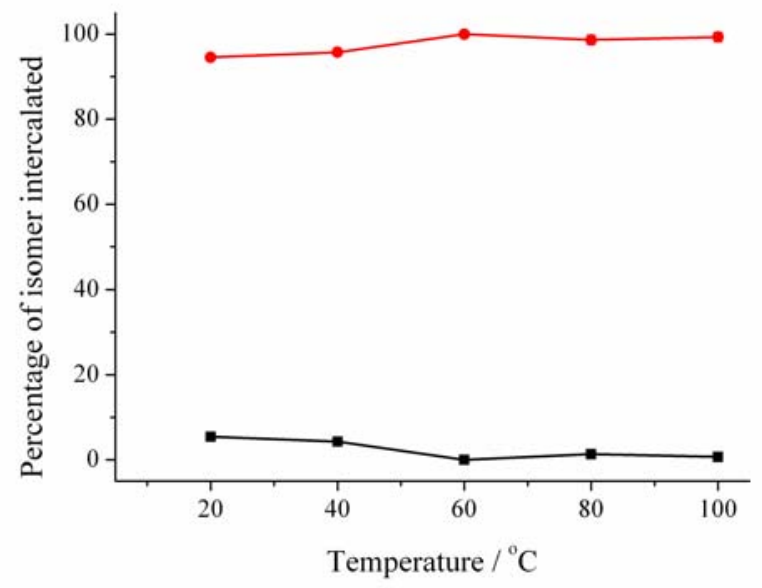

Figure 12: The results of the competitive intercalation of 1,2- (ם) and 1,4-BDC (O) into $\mathrm{Zn}_{5}-\mathrm{NO}_{3}$ for 6 days in water/acetone, with a 4-fold excess of guest employed. Experiments were performed in triplicate and mean \pm S.D. are plotted (error bars are so small as to be contained within the points on the graph here).

The influence of the excess of guest used for intercalation was also studied for 6-day reactions. The results are shown in Figure 13 (full data in Table S5). The excess of guest also has minimal influence on the extent of selectivity. Although use of a stoichiometric amount of BDCs resulted in a slight reduction in the selective uptake of 1,4-BDC at $20^{\circ} \mathrm{C}$, at all other temperatures the selectivity is identical within the error of the experiment. 


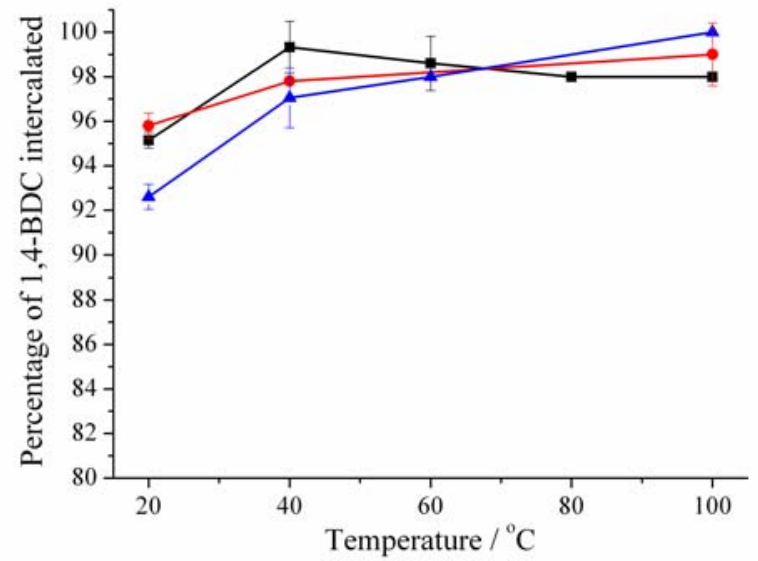

Figure 13: The effect of varying the excess of BDC used for competitive intercalation into $\mathrm{Zn}_{5}-\mathrm{NO}_{3}$. Data are shown as a function of temperature after reaction for 6 days in water, with a 4-fold excess $(\square)$, 2-fold excess (O) and stoichiometric amount ( $\mathbf{\Delta})$ of each guest employed for reaction. Experiments were performed in triplicate and mean \pm S.D. are plotted.

\section{Naphthalenedisulfonate guests}

More interesting selectivity trends are observed with the 1,5 and 2,6-NDS guests. Data for competitive reactions with a 4-fold excess of each guest for 6 days in water are shown in Figure 14. The HDS is found to be very selective for 2,6-NDS, with more than $90 \%$ of the intercalated guests comprising this isomer at all temperatures. This selectivity is higher than that observed for LDHs, and the reproducibility between experiments was found to be very high. The lowest selectivity is seen at 40 ${ }^{\circ} \mathrm{C}$, where $\mathrm{Zn}_{5}-\mathrm{NO}_{3}$ is $92 \%$ selective for 2,6-NDS; at all other temperatures virtually $100 \%$ selectivity is observed. Full numerical data are provided in the ESI, Table S6. The same trends are observed after 4 days of reaction (see Figure S11, Table S7). After 1 day of reaction, experiments performed at 20 and $100{ }^{\circ} \mathrm{C}$ showed that the HDS was $100 \%$ selective for 2,6-NDS at both temperatures, the same as observed for both 4 and 6 day reactions within the error of the experiment. Allowing the reaction to proceed for 23 days also resulted in $100 \%$ selectivity for 2,6-NDS at both 20 and 100 ${ }^{\circ} \mathrm{C}$. As with the BDC competition reactions, therefore, it is clear that the HDS is highly selective for NDS guests, and varying the reaction conditions has only a small effect on this. 


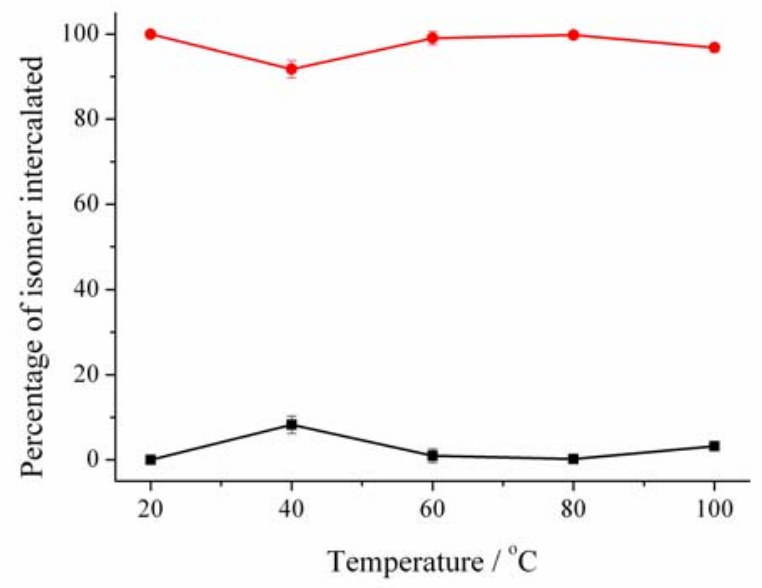

Figure 14: The results of the competitive intercalation of 1,5- (ם) and 2,6-NDS (O) into $\mathrm{Zn}_{5}-\mathrm{NO}_{3}$ for 6 days in water, with a 4-fold excess of guest employed. Experiments were performed in triplicate and mean \pm S.D. are plotted (error bars are so small as to be largely contained within the points on the graph here).

\section{Variation of the host material}

The above results indicate that the $\mathrm{Zn}_{5}-\mathrm{NO}_{3}$ is highly selective for both $1,4-\mathrm{BDC}$ and 2,6-NDS. Experiments were therefore performed to determine whether this selectivity is a phenomenon unique to this particular HDS, or whether other materials exhibit the same behaviour. The selectivity of the $\mathrm{Zn}_{5}-\mathrm{Cl}, \mathrm{Zn}_{5}$-acetate, $\mathrm{Zn}_{3} \mathrm{Ni}_{2}-\mathrm{NO}_{3}$ and $\mathrm{Zn}_{3.8} \mathrm{Co}_{1.2}-\mathrm{NO}_{3}$ materials was studied to allow the effect of both anion and cation variation to be probed. The results are given in Table 3, along with the comparable results for the $\mathrm{Zn}_{5}-\mathrm{NO}_{3}$ material. It can be seen that both anion and cation play a role in determining selectivity, but this is a relatively small effect. Considering the anion first, the $\mathrm{Zn}_{5}-\mathrm{X}$ materials exhibit selectivity for $1,4-\mathrm{BDC}$ at $20{ }^{\circ} \mathrm{C}$ in the order $\mathrm{Cl} \approx$ $\mathrm{NO}_{3}>$ acetate, and at $100{ }^{\circ} \mathrm{C}$ the trend is $\mathrm{Cl} \approx$ acetate $>\mathrm{NO}_{3}$. When varying the cations in the HDS, the selectivity trend is $\mathrm{Zn}_{5}-\mathrm{NO}_{3}>\mathrm{Zn}_{3.8} \mathrm{Co}_{1.2}-\mathrm{NO}_{3}>\mathrm{Zn}_{3} \mathrm{Ni}_{2}-\mathrm{NO}_{3}$ both at 20 and $100{ }^{\circ} \mathrm{C}$. Generally speaking, there is a small $(<4 \%)$ increase in selectivity as the temperature is raised from 20 to $100{ }^{\circ} \mathrm{C}$. The exception to this is $\mathrm{Zn}_{5}$-acetate, the least selective material at $20{ }^{\circ} \mathrm{C}(88.6 \% 1,4-\mathrm{BDC})$ but among the most selective at $100{ }^{\circ} \mathrm{C}\left(99.4 \%\right.$ 1,4-BDC). The $\mathrm{Zn}_{5}-\mathrm{NO}_{3}, \mathrm{Zn}_{5}-\mathrm{Cl}$ and $\mathrm{Zn}_{3.8} \mathrm{Co}_{1.2}-\mathrm{NO}_{3}$ HDSs are $c a .94-97 \%$ selective for $1,4-\mathrm{BDC}$ at $20{ }^{\circ} \mathrm{C}$, with this increasing to $97-$ $100 \%$ at $100{ }^{\circ} \mathrm{C}$. The $\mathrm{Zn}_{3} \mathrm{Ni}_{2}-\mathrm{NO}_{3}$ HDS is overall less selective, intercalating $90 \%$ 1,4-BDC at $20^{\circ} \mathrm{C}$ and this only increasing to $92 \%$ at $100{ }^{\circ} \mathrm{C}$. 
Table 3: The selectivity of some HDSs for 1,4-BDC after reaction with a 4-fold excess of each guest in water for 6 days. Data represent the mean and standard deviations (S.D.) of three independent experiments.

\begin{tabular}{ccccc}
\hline HDS & \multicolumn{2}{c}{$\mathbf{1 , 4 - B D C}$ intercalated at $\mathbf{2 0}{ }^{\circ} \mathbf{C}$} & \% 1,4-BDC intercalated at $\mathbf{1 0 0}{ }^{\circ} \mathbf{C}$ \\
\cline { 2 - 5 } & Mean & S.D. & Mean & S.D. \\
\hline $\mathrm{Zn}_{5}-\mathrm{NO}_{3}$ & 95.2 & 0.4 & 98 & 0.2 \\
$\mathrm{Zn}_{5}-\mathrm{Cl}$ & 97.0 & 2.1 & 99.4 & 0.6 \\
$\mathrm{Zn}_{5}$-acetate & 88.6 & 0.8 & 99.4 & 0.3 \\
$\mathrm{Zn}_{3} \mathrm{Ni}_{2}-\mathrm{NO}_{3}$ & 90.3 & 1.6 & 92.1 & 1.2 \\
$\mathrm{Zn}_{3.8} \mathrm{Co}_{1.2}-\mathrm{NO}_{3}$ & 93.7 & 0.8 & 97.5 & 0.6 \\
\hline
\end{tabular}

\section{Mechanistic study}

In order to study the mechanism underlying the observed selectivity in more detail, in situ energy-dispersive XRD experiments were performed in which the $\mathrm{Zn}_{5}-\mathrm{NO}_{3}$ HDS was reacted with a mixture of 1,2- and 1,4-BDC at 80 and $90{ }^{\circ} \mathrm{C}$. A 3D stacked plot showing the data obtained at $90{ }^{\circ} \mathrm{C}$ is given in Figure 15(a). As was discussed above, there is a distinct difference in the $\mathrm{d}_{200}$ values for the 1,2- and 1,4-BDC intercalates, with the former exhibiting $\mathrm{d}_{200}=15.5 \AA(32.2 \mathrm{keV})$ and the latter $14.6 \AA(34.3 \mathrm{keV})$. The plot in Figure 15(a) shows no intermediate phases and only one product reflection, at $34.3 \mathrm{keV}$ : typical of the 1,4-BDC intercalate. The EDXRD data collected at $80{ }^{\circ} \mathrm{C}$ also only contain a single product reflection corresponding to $\mathrm{Zn}_{5^{-}}$ 1,4-BDC. The selectivity for 1,4-BDC at this temperature is $c a .98 \%$. Given that 1,2BDC was found to intercalate more rapidly than the 1,4- analogue during in situ experiments using single guests, it might be postulated that the 1,2- isomer would intercalate first, and then over time be replaced by the 1,4-BDC isomer. However, the experimental data do not support this idea: it would appear that the reaction process is entirely thermodynamically controlled, and the only ion to intercalate is $1,4-B D C$. If a mixture of anions were to intercalate into a single particle, one would expect to observe the larger interlayer spacing from the two intercalates (i.e. the $15.5 \AA$ spacing associated with 1,2-BDC); alternatively, if the two guests intercalated into two different particles, two separate phases should be observed. PCA confirms that only one phase forms $\left(\mathrm{Zn}_{5}-1,4-\mathrm{BDC}\right)$, with no intermediate phases observable: data are included in Figure S12. Identical results were obtained for intercalation into $\mathrm{Zn}_{5^{-}}$ 
acetate, $\mathrm{Zn}_{5}-\mathrm{Cl}$ and $\mathrm{Zn}_{3.8} \mathrm{Co}_{1.2}-\mathrm{NO}_{3}$ : in all cases, only the 1,4-BDC intercalate is seen to form, with no evidence from EDXRD or PCA of any 1,2-BDC intercalating.

To verify the results of EDXRD, a second experiment was performed. The competitive intercalation of a 1:1 mixture of 1,2- and 1,4-BDC into $\mathrm{Zn}_{5}-\mathrm{NO}_{3}$ was allowed to proceed at $90{ }^{\circ} \mathrm{C}$, with aliquots removed at regular time points. The aliquots were quenched by rapid filtration, and the filtrate analysed by ${ }^{1} \mathrm{H}$ NMR spectroscopy. A known quantity of succinic acid was added as an internal standard, allowing the concentrations of 1,2- and 1,4-BDC at each time point to be calculated.

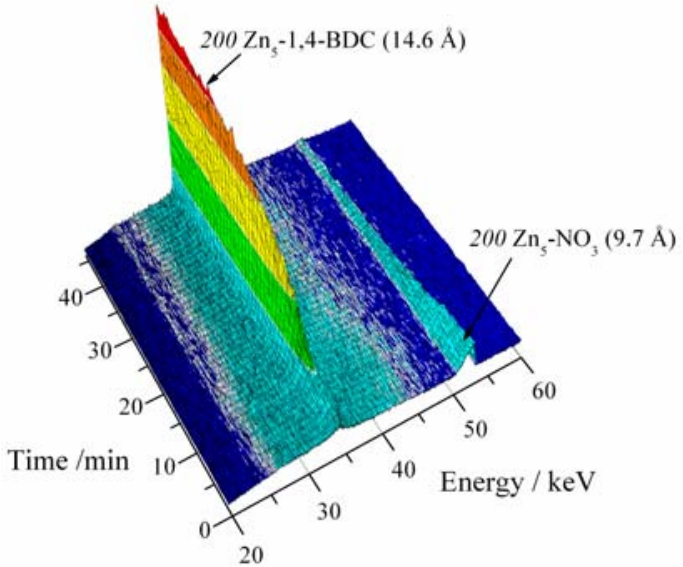

(a)

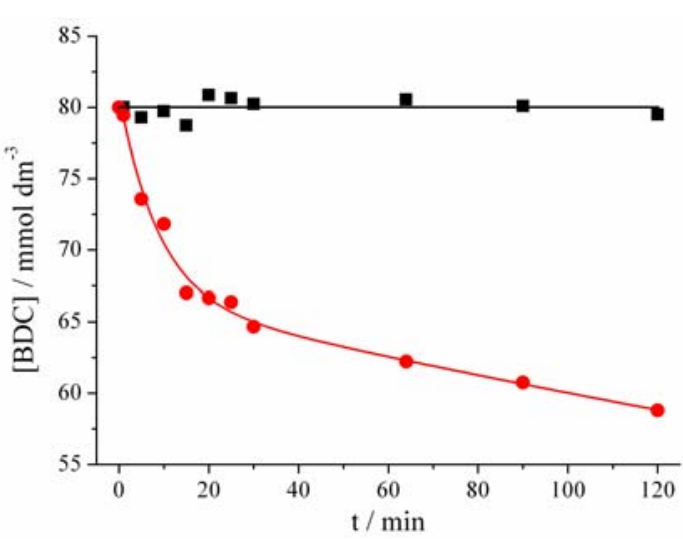

(b)

Figure 15: Time-resolved data for the competitive intercalation of a $1: 1$ mixture of 1,2- and 1,4-BDC into $\mathrm{Zn}_{5}-\mathrm{NO}_{3}$ at $90{ }^{\circ} \mathrm{C}$. (a) EDXRD data showing the formation of only the $\mathrm{Zn}_{5}-1,4-\mathrm{BDC}$ material, and (b) the concentrations of 1,2- (ם) and 1,4-BDC (O) in solution as determined by ${ }^{1} \mathrm{H}$ NMR.

The results of the NMR competition reaction are shown in Figure 15(b). It is clear that only the 1,4-BDC isomer is removed from solution. The concentration of 1,2-BDC remains constant and at the initial concentration throughout the reaction, whereas the 1,4-BDC concentration in solution declines rapidly. The amount of 1,4-BDC removed from solution after 120 minutes was calculated to be $0.83 \mathrm{mmol}$, essentially identical to the theoretical amount which can be taken up by the HDS $(0.82 \mathrm{mmol})$. These data, in conjunction with the EDXRD data, confirm that thermodynamic control is operational here: only the more favourable 1,4-BDC isomer is intercalated, even though 1,2-BDC intercalation is a more rapid process. 


\section{Discussion}

It is clear from the results reported here that under all conditions studied, HDSs show very high selectivity for 1,4-BDC over 1,2-BDC and 2,6-NDS over 1,5-NDS. Also there are only small differences in the extent of selectivity, all the HDSs investigated show essentially the same behaviour. The preferential intercalation of 1,4-BDC over 1,2-BDC has previously been reported for LDHs, and hence the results reported here are in full agreement with the literature. ${ }^{17,19,22,40}$ The intercalation of NDSs has been seen to be a relatively less selective process for LDHs $(60-95 \%$ of 1,5-NDS intercalated). ${ }^{20} \mathrm{Zn}_{5}-\mathrm{NO}_{3}$ is different, incorporating 2,6-NDS with a very high degree (>90\%) of selectivity. This result is in agreement with the previous work of Kadokawa, where selective intercalation of 2,6-naphthalenedicarboxylate over the 2,7-isomer was reported. ${ }^{11}$

The preferential intercalation of LDHs, particularly for the NDSs, is found to be highly dependent on temperature and solvent, whereas the role of both these factors appears to be small for HDSs. Increasing the temperature provokes only a small increase in selectivity for 1,4-BDC, and behaviour in water / acetone is essentially identical to that in a pure water solvent system. In addition, the reaction time and excess of guest used have only a small influence on the selectivity observed for the HDSs studied. A number of factors have been postulated to govern selectivity, including the solvation enthalpies of the incoming and exiting guest species, the electrostatic interactions between guest and host, and guest-guest interactions in the interlayer space. The subtle interplay between these factors has been invoked to explain the significant variation in selectivity with temperature and solvent observed for LDHs. ${ }^{20}$ The interactions between guest and solvent will be highly temperature and solvent dependent, whereas since the guests are held in a fairly rigid formation inside the interlayers of the host material the host/guest and guest/guest interactions will be relatively temperature independent. Therefore, it is suggested that, while solvation is important for LDHs, for HDSs the electrostatic interactions between the anionic guests and positive layers are the dominant factor in determining selectivity. This results in relatively minor temperature and solvent influences on the preferential intercalation patterns seen. 
It also appears from the results reported here that the mechanism of HDS selectivity is different to that of LDHs. Fogg et al. ${ }^{17}$ and Millange et al. ${ }^{19}$ have observed that initially both the isomers under investigation (e.g. 1,2- and 1,4-BDC) are intercalated into an $\mathrm{LDH}$, before the less preferred isomer (1,2-BDC) is later extruded and replaced by 1,4-BDC. In both cases, kinetic control thus operates at the early stages of reaction before thermodynamic control takes over later. However, from the results reported here, it would appear that for HDSs thermodynamic control governs the whole reaction: the EDXRD and NMR data demonstrate that only the 1,4-BDC intercalate forms, with no other products or intermediates being present on the reaction coordinate.

\section{Conclusions}

The organic guests 1,2- and 1,4-benzenedicarboxylate (1,2- and 1,4-BDC) and 1,5and 2,6-napthalanesulfonate (1,5- and 2,6-NDS) have been successfully intercalated into HDSs. Selected reactions were investigated by in situ X-ray diffraction, and the reactions observed to proceed directly from the host to the product under nucleation control. No intermediate phases were detected. The selective intercalation of isomeric pairs of guest anions was explored, and very high degrees of preferential intercalation found for 1,4- over 1,2-BDC and for 2,6- over 1,5-NDS. The selectivity was found to be largely invariant with reaction time, reaction temperature, solvent system, and guest concentration. It was also observed to be very similar across the range of HDSs studied. In situ diffraction and NMR demonstrate that the selective intercalation is a thermodynamically-controlled phenomenon.

\section{Acknowledgements}

The authors would like to thank the Deutsches Eleckronen-Synchrotron for the provision of beamtime on DORIS, and Dr Joern Donges and Dr Andre Rothkirch for their invaluable assistance during in situ experiments on F3. We are also indebted to Stephen Boyer of the London Metropolitan University for elemental microanalysis measurements. AMF thanks the Royal Society for a University Research Fellowship. 


\section{Supporting Information Available}

Full numerical data showing the selective intercalation observed under different conditions; EDXRD data for the intercalation of 1,4-BDC into $\mathrm{Zn}_{5}-\mathrm{Cl}$; additional PCA data; further plots showing selectivity variation with temperature for the competitive intercalation of 1,2- vs. 1,4-BDC and 1,5- vs. 2,6-NDS into $\mathrm{Zn}_{5}-\mathrm{NO}_{3}$. 


\section{References}

1. J. Fabri, U. Graeser and T. A. Simo, in Ullmann's Encyclopedia of Industrial Chemistry, Wiley, 2000.

2. R. J. Sheehan, in Ullmann's Encyclopedia of Industrial Chemistry, Wiley, 2011.

3. G. Booth, in Ullmann's Encyclopedia of Industrial Chemistry, Wiley, 2000.

4. M. Meyn, K. Beneke and C. Lagaly, Inorg. Chem., 1993, 32, 1209.

5. J. T. Rajamathi, S. Britto and M. Rajamathi, J. Chem. Sci., 2005, 117, 629.

6. S. Yamanaka, T. Sako, K. Seki and M. Hattori, Solid State Ionics, 1992, 53, 527.

7. T. Hara, M. Ishikawa, J. Sawada, N. Ichikuni and S. Shimazu, Green Chem., 2009, 11, 2034.

8. J. T. Rajamathi, N. H. Raviraj, M. F. Ahmed and M. Rajamathi, Solid State Sci., 2009, 11, 2080.

9. R. Rojas, M. A. Ulibarri, C. Barriga and V. Rives, Microporous Mesoporous Mater., 2008, 112, 262.

10. T. Hara, J. Kurihara, N. Ichikuni and S. Shimazu, Chem. Lett., 2010, 39, 304305 .

11. H. Tagaya, N. Sasaki, H. Morioka and J. Kadokawa, Mol. Cryst. Liquid Cryst., 2000, 341, 413.

12. E. Kandare and J. M. Hossenlopp, J. Phys. Chem. B, 2005, 109, 8469-8475.

13. H. Morioka, H. Tagaya, M. Karasu, J.-i. Kadokawa and K. Chiba, J. Mater. Res., 1998, 13, 848.

14. S. P. Newman and W. Jones, J. Solid State Chem., 1999, 148, 26.

15. J. Tronto, F. Leroux, M. Dubois, C. Taviotgueho and J. Valim, J. Phys. Chem. Solids, 2006, 67, 978.

16. E. Delayahe, S. Eyele-Mezui, J. F. Bardeau, C. Leuvrey, L. Mager, P. Rabu and G. Rogez, J. Mater. Chem., 2009, 19, 6106.

17. A. M. Fogg, J. S. Dunn, S.-G. Shyu, D. R. Cary and D. O'Hare, Chem. Mater., 1998, 10, 351.

18. L. Li, N. Zhang, S. J. Liu and D. Z. Chen, J. Phys. Chem. Solids, 2005, 66, 1844.

19. F. Millange, R. I. Walton, L. Lei and D. O'Hare, Chem. Mater., 2000, 12, 1990.

20. G. R. Williams, T. G. Dunbar, A. J. Beer, A. M. Fogg and D. O'Hare, J. Mater. Chem., 2006, 16, 1231.

21. A. Ragavan, A. I. Khan and D. O'Hare, J. Mater. Chem., 2006, 16, 602.

22. L. X. Lei, A. Khan and D. O'Hare, J. Solid State Chem., 2005, 178, 3648.

23. L. Lei, F. Millange, R. I. Walton and D. O'Hare, J. Mater. Chem., 2000, 10, 1881.

24. A. Ragavan, A. Khan and D. O'Hare, J. Mater. Chem., 2006, 16, 4155-4155.

25. B. Lotsch, F. Millange, R. I. Walton and D. O'Hare, Solid State Sci., 2001, 3, 883.

26. S. W. Rhee, J. H. Lee and D. Y. Jung, J. Colloid Interface Sci., 2002, 245, 349.

27. T. Kameda, T. Yamazaki and T. Yoshioka, Mater. Res. Bull., 2010, 45, 751.

28. N. Thomas and M. Rajamathi, J. Colloid Interface Sci., 2011, 362, 493.

29. N. Thomas and M. Rajamathi, J. Mater. Chem., 2011, 21, 18077. 
30. N. Kozai, T. Ohnuki and S. Komarneni, J. Mater. Res., 2002, 17, 2993.

31. G. R. Williams, A. J. Norquist and D. O'Hare, Chem. Mater., 2004, 16, 975.

32. J. C. Burley, D. O'Hare and G. R. Williams, Anal. Methods, 2011, 3, 814.

33. R: A language and environment for statistical computing. R Development Core Team, Vienna, 2011.

34. P. Benito, M. Herrero, F. M. Labajos and V. Rives, Appl. Clay Sci., 2010, 48, 218.

35. S. Gago, M. Pillinger, T. M. Santos and I. S. Goncalves, Ceram.-Silikaty, 2004, 48, 155.

36. M. Herrero, S. Martinez-Gallegos, F. M. Labajos and V. Rives, J. Solid State Chem., 2011, 184, 2862.

37. S. F. Hulbert, J. Br. Ceram. Soc., 1969, 6, 11.

38. Y. Du and D. O'Hare, Inorg. Chem., 2008, 47, 11839.

39. G. R. Williams, T. G. Dunbar, A. J. Beer, A. M. Fogg and D. O'Hare, J. Mater. Chem., 2006, 16, 1222.

40. A. M. Fogg, V. M. Green, H. G. Harvey and D. O'Hare, Adv. Mater., 1999, 11, 1466. 